\title{
Synthesis and Thermoelectric Properties of Noble Metal Ternary Chalcogenide Systems of Ag-Au-Se in the forms of Alloyed Nanopar- ticles and Colloidal Nanoheterostructures
}

Mariona Dalmases, ${ }^{\dagger, \ddagger}$ Maria Ibáñez, \&,\$ Pau Torruella, ${ }^{\#, \ddagger}$ Víctor Fernàndez-Altable, ${ }^{\# \text { Lluís }}$ López-Conesa, ${ }^{\#, \ddagger}$ Doris Cadavid, ${ }^{\perp}$ Laura Piveteau, ${ }^{\&, \$}$ Maarten Nachtegaal, ${ }^{\propto}$ Jordi Llorca, ${ }^{\diamond}$ Maria Luisa Ruiz-González, Sònia Estradé, ${ }^{\#, \ddagger}$ Francesca Peiró, ${ }^{\#, \ddagger}$ Maksym V. Kovalenko, ${ }^{\&, \$}$ Andreu Cabot $^{\perp, \bullet}$ and Albert Figuerola*,†,

${ }^{\dagger}$ Departament de Química Inorgànica i Orgànica, Secció de Química Inorgànica, Universitat de Barcelona, Martí i Franquès 1-11, 08028 Barcelona, Spain

${ }^{\ddagger}$ Institut de Nanociència i Nanotecnologia (IN2UB), Universitat de Barcelona, Martí i Franquès 1-11, 08028 Barcelona, Spain

${ }^{\&}$ Institute of Inorganic Chemistry, Department of Chemistry and Applied Biosciences, ETH Zürich, Vladimir Prelog Weg 1, CH-8093, Switzerland

${ }^{\$}$ Empa-Swiss Federal Laboratories for Materials Science and Technology, Dübendorf, Überlandstrasse 129, $\mathrm{CH}-$ 860o, Switzerland

\# Laboratory of Electron Nanoscopies (LENS)-MIND/IN2UB, Departament d'Electrònica, Universitat de Barcelona, Martí i Franquès 1-11, 08028 Barcelona, Spain

- ICFO-The Institute of Photonic Sciences, Mediterranean Technology Park, Av. Carl Friedrich Gauss, 3, o886o Castelldefels, Spain

${ }^{\perp}$ Catalonia Energy Research Institute - IREC, Sant Adrià de Besòs, o8930 Barcelona, Spain

${ }^{\propto}$ Paul Scherrer Institute, 5232 Villigen PSI, Switzerland

${ }^{\diamond}$ Institut de Tècniques Energètiques i Centre de Recerca en NanoEnginyeria, Universitat Politècnica de Catalunya, Av. Diagonal, 647, o8028 Barcelona, Spain

- Departamento de Química Inorgánica, Facultad de Químicas, Universidad Complutense (UCM), CEI Moncloa, 28040 Madrid, Spain

- Institució Catalana de Recerca i Estudis Avançats - ICREA, o801o Barcelona, Spain

KEYWORDS Heteronanostructure, colloid, metal, semiconductor, gold, silver selenide, hybrids, ternary materials, alloy, nanoparticles, nanocomposite, thermoelectricity.

ABSTRACT: The optimization of a material functionality requires both the rational design and precise engineering of its structural and chemical parameters. In this work, we show how colloidal chemistry is an excellent synthetic choice for the synthesis of novel ternary nanostructured chalcogenides, containing exclusively noble metals, with tailored morphology and composition and with potential application in the energy conversion field. Specifically, the Ag-Au-Se system has been explored from a synthetic point of view, leading to a set of $\mathrm{Ag}_{2} \mathrm{Se}$-based hybrid and ternary nanoparticles, including the room temperature synthesis of the rare ternary $\mathrm{Ag}_{3} \mathrm{AuSe}_{2}$ fischesserite phase. An in-depth structural and chemical characterization of all nanomaterials has been performed, which proofed especially useful for unravelling the reaction mechanism behind the formation of the ternary phase in solution. The work is complemented with the thermal and electric characterization of a ternary Ag-Au-Se nanocomposite with promising results: we found that the use of the ternary nanocomposite represents a clear improvement in terms of thermoelectric energy conversion as compared to a binary Ag-Se nanocomposite analogue.

INTRODUCTION
The controlled combination of multiple phases or materials at the nanometer level forming nanocomposites has revealed advantageous in many fields due to the ap- 
pearance of synergetic phenomena. As a matter of fact, nanocomposites have been claimed to be responsible for the longer durability of electrocatalysts in rechargeable batteries, ${ }^{1,2}$ for the improved extraction of photogenerated current in depleted heterojunction quantum dot-based solar cells, ${ }^{3,4}$ for the enhanced light-extraction efficiency and color tunability in quantum dot-based light emitting diodes, ${ }^{5}$ and for the higher electrical conductivity, lower thermal conductivity and enhanced Seebeck coefficient in thermoelectric devices, to mention a few examples. ${ }^{6-13}$ One way to fabricate such functional nanocomposites is by exploiting the bottom-up assembly of pre-made tailored nanoparticles (NPs). In this regard, the synthesis of morphologically, structurally and compositionally tailored homogeneous NPs becomes a must, and the adequate choice of a synthetic method that can fulfill these requirements shows up as a critical issue.

Lying at the interface between solid-state and molecular chemistries, modern colloidal synthesis appears to be unique in several regards. Besides controlling size and shape of NPs, it allows sequential deposition of several materials in the form of a single hybrid NP, it fully exploits unconventional reactivity of nanomaterials such as cation or anion exchange, and it stabilizes metastable phases. ${ }^{14-23}$ Thus, the formation of heterostructures with appropriate interfaces and the fine control over their chemical composition are reasonable aspects to be achieved by means of colloidal chemistry, and definitely key factors for further developments. ${ }^{16,24,25}$ Just as a tiny fraction of numerous examples, type II-semiconductor heterostructures such as CdSe@CdTe multibranched NPs, metal-semiconductor hybrid systems such as $\mathrm{Au}(\mathrm{Pt})-\mathrm{CdSe}$ nanodumbbells or $\mathrm{Au}(\mathrm{Pt})-\mathrm{Cu}_{2} \mathrm{ZnSnS}_{4} \mathrm{NPs}$, bimetallic core@shell Co@Cu or FePd@Pd nanostructures and narrow band gap semiconductor core-shell PbTe@PbS NPs have shown to be efficient systems for optoelectronic, catalytic and thermoelectric applications. ${ }^{26-33}$ Furthermore, colloidal NPs can then be used as pre-engineered building blocks for constructing a nanostructured extended solid with virtually unlimited control over its compositional and morphological features. ${ }^{25,34,35}$ The most straightforward advantage of this method resides in the fact that a sub-nanometer compositional control is achieved already in the building blocks before the formation of the final composite, guaranteeing a high homogeneity in the latter. On the whole, colloidal synthesis routes and bottom-up assembly procedures allow simultaneous atomic- and nanoscale-control over chemical composition and morphology of inorganic NPs and derived nanocomposites, opening new avenues in optoelectronic and energy applications. ${ }^{36-38}$

Silver chalcogenides are low band gap semiconductor materials that are currently drawing much attention in several fields. Tunable emission in the near-infrared (NIR) spectral range is of potential value for biosensing and in vivo imaging, whereas solids of such materials can be utilized as photodetectors. ${ }^{39-42}$ Their efficient charge transport, superionic character and high magnetoresistance have motivated the study of their use as solid electrolytes for electrochemical applications as well as magnetic sensors. ${ }^{43,44}$ Binary silver chalcogenides have also been tested as thermoelectric materials, showing values of the thermoelectric figure of merit $(Z T)$ close to unity in some cases. ${ }^{45-49}$ In the context of thermoelectrics, Xiao et al. have reported higher $Z T$ values for ternary $\mathrm{Ag}_{4} \mathrm{SeS}$ alloyed NPs, compared to the binary $\mathrm{Ag}_{2} \mathrm{Se} N \mathrm{NPs}^{50}$ Other materials in the research spotlight are $\mathrm{CuAgSe}$, $\mathrm{AgSbSe}_{2}$ and $\mathrm{AgBiSe}_{2}$ systems, which are currently emerging as promising thermoelectric materials with enhanced ionic and electronic mobilities and ultra-low thermal conductivities. ${ }^{51-54}$ Very little, however, is known about noble metal derivatives of nanocrystalline silver chalcogenides, besides the possibility to prepare a few hybrid nanostructures..$^{55-57}$

Interestingly, the ternary phase diagram of $\mathrm{Au}, \mathrm{Ag}$ and Se shows the existence of a room-temperature stable ternary compound called fischesserite, with chemical formula $\mathrm{Ag}_{3} \mathrm{AuSe}_{2}$. Fischesserite is a naturally occurring mixed gold-silver selenide that crystallizes in a cubic system, with a space grup $I_{4,32}$. The mineral was initially isolated from nature ${ }^{8,59}$ and later synthetically obtained by reacting $\mathrm{Ag}_{2} \mathrm{Se}$ precipitates and thio-gold(I) complexes, or alternatively by a direct solid-state reaction of the elements. ${ }^{60,61}$ Bulk fischesserite has been identified as a semiconductor with an energy gap of about $0.2 \mathrm{eV} .^{62}$

In this work, we sought to explore a ternary Ag-Au-Se system in the form of colloidal nanomaterials. Starting from binary system, $\mathrm{Ag}_{2} \mathrm{Se} \mathrm{NPs}$, we show how they can be transformed into alloyed and heterostructured NPs with controlled composition, and present detailed structural characterization of the obtained. Furthermore, we compare thermoelectric properties of a novel ternary Ag-AuSe nanocomposite with the ones of the binary $\mathrm{Ag}_{2} \mathrm{Se}$ analogue.

\section{EXPERIMENTAL SECTION}

Chemicals. Silver chloride ( $\mathrm{AgCl}, 99.9 \%)$, selenium powder (Se, 99.99\%), and tri-n-octylphosphine (TOP, 97\%) were obtained from Strem Chemicals. Gold (III) chloride trihydrate $\left(\mathrm{HAuCl}_{4} \cdot 3 \mathrm{H}_{2} \mathrm{O}, \geq 99.9 \%\right)$, oleylamine (OLAm, 70\%), dodecylamine (DDA, 98\%), tri-n-octylphosphine oxide (TOPO, 99\%), and toluene (99.9\%) were purchased from Sigma-Aldrich. Ethanol (EtOH, 96\% v/v) was obtained from Panreac. Butanol (BuOH, 99.9\%) was obtained from Alfa Aesar. All the reagents and solvents were used without further purification.

Synthesis of $\mathrm{Ag}_{2} \mathrm{Se} \mathrm{NPs}$. The synthesis of $\mathrm{Ag}_{2} \mathrm{Se} \mathrm{NPs}$ was adapted from that published by Sahu and co-workers. ${ }^{63}$ Briefly, $7.8 \mathrm{~g}$ TOPO and $6.6 \mathrm{~mL}$ OLAm were degassed under vacuum at $120{ }^{\circ} \mathrm{C}$ for 30 minutes. Meanwhile, two precursor solutions were prepared in the glovebox: 474 $\mathrm{mg}(6 \mathrm{mmol})$ Se were dissolved in $6 \mathrm{~mL}$ TOP and $572 \mathrm{mg}$ (4 mmol) $\mathrm{AgCl}$ were dissolved in $4 \mathrm{~mL}$ TOP. Under $\mathrm{N}_{2}$ 
atmosphere, the temperature was raised to $180{ }^{\circ} \mathrm{C}$ and the TOP-Se solution was injected. Once the temperature was recovered the $\mathrm{AgCl}-\mathrm{TOP}$ precursor solution was injected. After 20 minutes of reaction, the heating was stopped and the solution was let cool naturally. Once at $50^{\circ} \mathrm{C} 5 \mathrm{~mL}$ of $\mathrm{BuOH}$ was added to the reaction flask to avoid solidification of the solvent. Finally, the solution was washed three times with $\mathrm{EtOH}$, centrifuging 4 minutes at $4500 \mathrm{rpm}$ and re-dispersing with $4 \mathrm{~mL}$ toluene.

Phase transfer of Au(III) ions from water to toluene. The phase transfer of $\mathrm{Au}(\mathrm{III})$ ions from water to toluene was based on the protocol reported by Yang and coworkers $^{64}$ as follows: for the preparation of a $1 \mathrm{mM}$ $\mathrm{Au}(\mathrm{III})-\mathrm{DDA}$ stock solution, $40 \mathrm{mg}$ (0.1 $\mathrm{mmol})$ $\mathrm{HAuCl}_{4} \cdot 3 \mathrm{H}_{2} \mathrm{O}$ were dissolved in $100 \mathrm{~mL}$ deionized water and mixed with $1.61 \mathrm{~g}$ (8.6 mmol) DDA dissolved in 100 $\mathrm{mL}$ EtOH. After 3 minutes of stirring, $100 \mathrm{~mL}$ toluene were added to the solution and the stirring was kept for 3 more minutes. The toluene phase was separated and washed twice with $50 \mathrm{~mL}$ of $\mathrm{H}_{2} \mathrm{O}: \mathrm{EtOH}$ 1:1 mixture in order to avoid the precipitation of silver chlorides in further reactions with $\mathrm{Ag}_{2} \mathrm{Se}$ NPs. This solution is stable for 3-4 days. The preparation of more concentrated Au(III) solutions was adapted from the procedure above using proportionally increased amounts of $\mathrm{HAuCl}_{4} \cdot 3 \mathrm{H}_{2} \mathrm{O}$ and DDA.

The preparation of $6 \mathrm{mM} A \mathrm{Au}(\mathrm{III})$-TOAB stock solution was adapted from the protocol described in the previous paragraph by using $1.5 \mathrm{~g}$ of TOAB $(2.7 \mathrm{mmol})$ instead of DDA and $240 \mathrm{mg}(0.6 \mathrm{mmol})$ of $\mathrm{HAuCl}_{4} \cdot 3 \mathrm{H}_{2} \mathrm{O}$ instead of only $40 \mathrm{mg}$.

Synthesis of $\mathrm{Ag}_{3} \mathrm{AuSe}_{2}$ NPs. $180 \mu \mathrm{L} \mathrm{Ag}_{2} \mathrm{Se}$ NPs solution $(3.6 \mu \mathrm{M})$ were mixed with $2 \mathrm{~mL}$ of a $6 \mathrm{mM} \mathrm{Au}(\mathrm{III})-\mathrm{TOAB}$ stock solution in toluene and shaken for $1 \mathrm{~h}$. After this time, the final solution was washed once with EtOH and the NPs re-dispersed in toluene.

Synthesis of dimer-like $\mathrm{Au}-\mathrm{Ag}_{2} \mathrm{Se}$ and $\mathrm{Au}-\mathrm{Ag}_{3} \mathrm{AuSe}_{2}$ hybrid NPs. 18o $\mu \mathrm{L} \mathrm{Ag}_{2}$ Se NPs solution $(3.6 \mu \mathrm{M})$ were mixed with $3 \mathrm{~mL}$ of a $\mathrm{Au}(\mathrm{III})$-DDA stock solution in toluene, and mechanically shaken during a specific time. After this time, the final solution was washed once with EtOH and the NPs re-dispersed in toluene. For the synthesis of $\mathrm{Au}-\mathrm{Ag}_{2} \mathrm{Se}$ hybrid NPs the concentration of $\mathrm{Au}(\mathrm{III})$-DDA stock solution was $1 \mathrm{mM}$ and the reaction time was 30 seconds, whereas for $\mathrm{Au}-\mathrm{Ag}_{3} \mathrm{AuSe}_{2}$ hybrid NPs the concentration was $6 \mathrm{mM}$ and the reaction time 30 minutes.

\section{Characterization methods.}

TEM characterization. $\mathrm{Ag}_{2} \mathrm{Se}, \mathrm{Ag}_{3} \mathrm{AuSe}_{2}, \mathrm{Au}-\mathrm{Ag}_{2} \mathrm{Se}$ and $\mathrm{Au}-$ $\mathrm{Ag}_{3} \mathrm{AuSe}_{2} \mathrm{NP}$ samples were prepared for observation by dilution in toluene followed by sonication. A droplet of the solution was then poured in holey carbon covered copper TEM grids. The sintered pellets used in the thermoelectric measurements where thinned to electron transparency using the Focused Ion Beam in situ lift-out technique. A Hitachi H8ooMT conventional transmission electron microscope (TEM) equipped with Bioscan Gatan camera and tungsten filament, operating at an accelerating voltage of $200 \mathrm{kV}$ and $3 \mu \mathrm{m}$ spot size was used for the morphological study of all synthesized nanostructures. Images were recorded with Digital Micrograph v.1.82.80 software. Further TEM and HRTEM images of $\mathrm{Ag}_{2} \mathrm{Se}$, $\mathrm{Ag}_{3} \mathrm{AuSe}_{2}, \mathrm{Au}-\mathrm{Ag}_{2} \mathrm{Se}$ and $\mathrm{Au}-\mathrm{Ag}_{3} \mathrm{AuSe}_{2} \mathrm{NPs}$ and pellets were acquired in a Jeol JEM 2100 equipped with a $\mathrm{LaB}_{6}$ source and with a Jeol JEM 2010F equipped with a FEG gun, both operated at $200 \mathrm{kV}$. HAADF and EDX measurements for $\mathrm{Au}-\mathrm{Ag}_{2} \mathrm{Se}$ NPs were performed in a probe corrected FEI Titan3 instrument, equipped with an X-FEG source and a Bruker EDX analyzer. HAADF and EELS measurements for $\mathrm{Au}-\mathrm{Ag}_{3} \mathrm{AuSe}_{2}$ NPs were performed in a probe corrected JEOL ARM-2oo equipped with a coldFEG source and a Quantum GIF EELS spectrometer. HAADF and HRTEM image simulations were carried out using the TEMSIM open source image simulation software. ${ }^{65}$ Crystal cells for simulation were built using the Rhodius software. ${ }^{66,67}$

A Cary 100 Scan 388 Varian UV-Vis spectrophotometer was used with quartz cuvettes for optical characterization. The instrument was commanded with Varian UV v.3.33.

X-ray diffraction (XRD) spectra were acquired with a PANalytical X'Pert Pro MPD Alphaı diffractometer operating in $\theta / 2 \theta$ geometry at $45 \mathrm{kV}, 40 \mathrm{~mA}$ and $\lambda=$ $1.5406 \AA(\mathrm{Cu} \mathrm{K} \alpha 1)$. Thin layers of the samples were prepared by drop casting and evaporation of the solvent on a monocrystalline Si holder of $15-\mathrm{mm}$ diameter and $0.15 \mathrm{~mm}$ height. Scans in the range $2 \theta=4-100^{\circ}$ were run at a step size of $2 \theta=0.017^{\circ}$ and 100 s per step. The data were treated with X'Pert HighScore Plus software.

X-ray photoelectron spectroscopy (XPS) was performed on a SPECS system equipped with an $\mathrm{Al}$ anode $\mathrm{XR}_{50}$ source operating at $150 \mathrm{~W}$ and a Phoibos 150 MCD-9 detector. The pass energy of the hemispherical analyzer was set at $25 \mathrm{eV}$ and the energy step was set at $0.1 \mathrm{eV}$. The binding energy (BE) values were referred to the $C$ is peak at $284.8 \mathrm{eV}$.

Field Emission Scanning Electron Microscopy (FESEM) images were recorded on a Zeiss Neon4o scanning electron microscope Crossbeam Station equipped with a field emission electron source operating at $5 \mathrm{kV}$.

The composition and concentration of the NPs solutions was determined by Inductively Coupled Plasma-Atomic Emission Spectroscopy (ICP-AES). The measurements were carried out by an Optima 3200 RL Perkin Elmer spectrometer. For these measurements, $50 \mu \mathrm{L}$ of each of the solutions were precipitated in $\mathrm{MeOH}$ and redispersed in $\mathrm{CHCl}_{3}$. The solution was evaporated in an oven overnight at $90{ }^{\circ} \mathrm{C} .2 .5 \mathrm{~mL} \mathrm{HNO}_{3}$ and $0.7 \mathrm{~mL} \mathrm{H}_{2} \mathrm{O}_{2}$ were added to the precipitate before the vial was sealed and then heated to $90{ }^{\circ} \mathrm{C}$ for $72 \mathrm{~h}$. The resulting solution was transferred to a $25 \mathrm{~mL}$ volumetric flask and diluted with milliQ water.

XAS measurements were carried out at the XioDA (SuperXAS) beamline at the Swiss Light Source, Villigen, Switzerland, which operated with a ring current of approximately $400 \mathrm{~mA}$ in top-up mode. The polychromatic radiation from the superbend magnet, with a magnetic field of $2.9 \mathrm{~T}$ and critical energy of $11.9 \mathrm{keV}$, was mono- 
chromatized using a channel cut $\mathrm{Si}(311)$ crystal monochromator. Spectra were collected on pressed pellets optimized to 1 absorption length at the Ag K-edge (25515 $\mathrm{eV})$ respectively at the $\mathrm{Au} \mathrm{L}_{3}$-edge $(11919 \mathrm{eV})$ in transmission mode, using $15 \mathrm{~cm}$ long Ar filled ionization chambers at the Ag K-edge and $\mathrm{N}_{2}$ filled ionization chambers at the $\mathrm{L}_{3}$ edge. The beamline energy
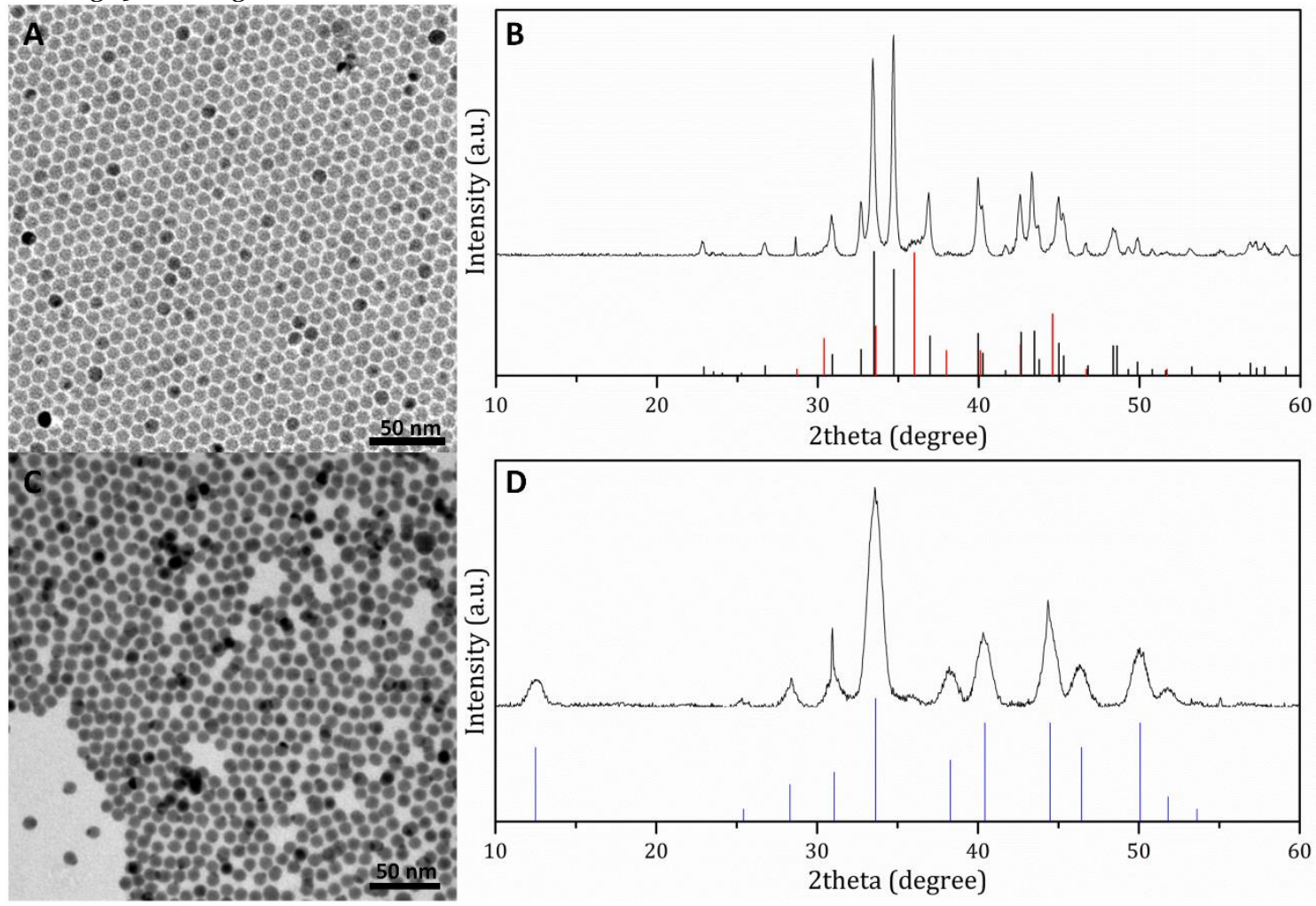

Figure 1. (A) TEM micrograph of $\mathrm{Ag}_{2} \mathrm{Se}$ NPs. (B) XRD spectrum of $\mathrm{Ag}_{2} \mathrm{Se}$ NPs, $\beta$ - $\mathrm{Ag}_{2} \mathrm{Se}$ (JCPDS oo-024-1041, black) reference pattern and $t$ - $\mathrm{Ag}_{2}$ Se calculated (red) pattern. ${ }^{6}$ (C) TEM images of $\mathrm{Ag}_{3} \mathrm{AuSe}_{2} \mathrm{NPs}$. (D) XRD spectrum of $\mathrm{Ag}_{3} \mathrm{AuSe}_{2} \mathrm{NPs}_{\mathrm{and}} \mathrm{Ag}_{3} \mathrm{AuSe}_{2}$ (JCPDS o1-072-0392, blue) reference pattern.

axis was calibrated with an $\mathrm{Ag}$ or Au reference foil respectively. Measurements were performed at ambient conditions. XAS spectra were treated with the iFeffit software suite. $^{69}$ The XAS spectra were normalized and background-corrected. At this stage the spectra were ready for performing Linear Combination Fitting (LCF).

Thermoelectric characterization. Electric properties. The pressed samples were polished, maintaining the diskshape morphology. Final pellets had a $10 \mathrm{~mm}$ diameter and were approximately $1 \mathrm{~mm}$ thick. The Seebeck coefficient was measured using a static DC method. Electrical resistivity data were obtained by a standard four-probe method. Both the Seebeck coefficient and the electrical resistivity were simultaneously measured with accuracies better than $1 \%$ in a LSR-3 LINSEIS system from room temperature to $850 \mathrm{~K}$, under helium atmosphere. Samples were held between two alumel electrodes and two probe thermocouples with spring-loaded pressure contacts. A resistive heater on the lower electrode created temperature differentials in the sample to determine the Seebeck coefficient. Thermal properties. An XFA 600 Xenon Flash Apparatus was used to determine the thermal diffusivities of all samples with an accuracy of $c a$. $6 \%$. Total thermal conductivity $(\kappa)$ was calculated using the relation $\kappa=$
$D C_{p} \rho$, where $D$ is the thermal diffusivity, $C_{p}$ is the heat capacity, and $\rho$ is the mass density of the pellet. The $\rho$ values were calculated using the Archimedes method. The specific heat $\left(C_{p}\right)$ of the samples was measured using a Differential Scanning Calorimeter DSC 204 F1 Phoenix from NETZSCH.

\section{RESULTS AND DISCUSSION}

\section{$\mathrm{Ag}_{2} \mathrm{Se}$ precursor NPs \& ternary $\mathrm{Ag}_{3} \mathrm{AuSe}_{2} \mathrm{NPs}$}

Our synthetic approach starts from the preparation of monodisperse $\mathrm{Ag}_{2} \mathrm{Se} \mathrm{NPs}$ that will further react with a specific $\mathrm{Au}(\mathrm{III})$-surfactant complex at room temperature in order to obtain nanostructures with an increasing degree of complexity. $\mathrm{Ag}_{2} \mathrm{Se}$ NPs were synthesized following a hot injection method published by Sahu and coworkers. ${ }^{63}$ Briefly, trioctylphosphine oxide (TOPO) and oleylamine (OLAm) were firstly degassed under vacuum at $120{ }^{\circ} \mathrm{C}$. Under $\mathrm{N}_{2}$ atmosphere, the temperature was raised to $180{ }^{\circ} \mathrm{C}$ and a trioctylphosphine (TOP) - Se solution was injected. Once the initial temperature was recovered, a AgCl-TOP solution was injected and the reaction mixture was kept at this temperature for 20 minutes. 
Transmission electron microscopy (TEM) images of assynthesized $\mathrm{Ag}_{2} \mathrm{Se}$ NPs are shown in Figure ${ }_{1} \mathrm{~A}$ and $\mathrm{S}_{1}$ of the Supporting Information (SI). NPs are hexagonal in shape and around $11 \mathrm{~nm}$ in average diameter, with a standard deviation of $4.3 \%$. TEM measurements show that, although the sample is mainly consisting of single crystal NPs, one small darker area could be spotted in a minor portion of the NPs composing the sample, indicating the presence of a few two-domain

Scheme 1. General strategy for the synthesis of alloyed and hybrid NPs based on the Ag-Au-Se ternary system.

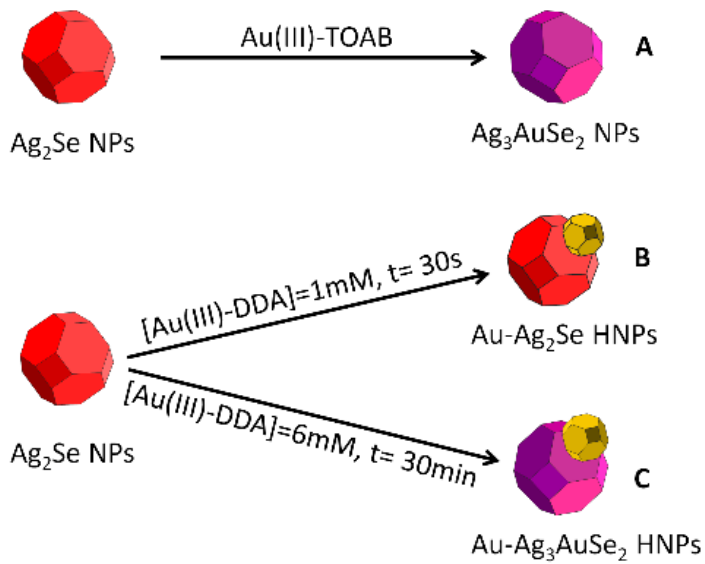

nanostructures. High resolution TEM (HRTEM) micrographs confirm that both domains exhibit characteristic sets of planes of the orthorhombic $\beta-\mathrm{Ag}_{2} \mathrm{Se}$ lattice, as shown in Figure $\mathrm{S}_{2}$, indicating that the NPs are formed exclusively of $\mathrm{Ag}_{2} \mathrm{Se}$ semiconductor material, regardless of their single crystal or polycrystalline character. Nanostructured $\mathrm{Ag}_{2} \mathrm{Se}$ has three known crystallographic phases: an orthorhombic phase $\left(\beta-\mathrm{Ag}_{2} \mathrm{Se}\right)$ which is stable at low temperature, a cubic phase $\left(\alpha-\mathrm{Ag}_{2} \mathrm{Se}\right)$ stable above $135{ }^{\circ} \mathrm{C}$, and a metastable tetragonal phase $\left(t-\mathrm{Ag}_{2} \mathrm{Se}\right)$ only observed in NPs. ${ }^{70}$ The X-ray diffraction (XRD) spectrum in Figure ${ }_{1 B} \mathrm{~B}$ indicates that the obtained NPs present mainly the orthorhombic phase in agreement with HRTEM analysis, although $t-\mathrm{Ag}_{2} \mathrm{Se}$ can also be identified as a minor product. However, depending on the Se:Ag ratio used in the synthesis, one of the two phases can prevail in the final sample: while mostly $\beta-\mathrm{Ag}_{2} \mathrm{Se}$ is obtained with a 3:2 ratio (Figure $1 \mathrm{~B}$ ), a ratio of 2:1 favors the formation of $t-\mathrm{Ag}_{2} \mathrm{Se}$ NPs (although metallic Ag is also formed as a side product in the latter case) as shown in the XRD spectrum in Figure $S_{3}$.

The formation of ternary $\mathrm{Ag}_{3} \mathrm{AuSe}_{2}$ NPs takes place by the reaction of the pre-synthesized $\mathrm{Ag}_{2} \mathrm{Se} \mathrm{NPs}$ with a $\mathrm{Au}(\mathrm{III})$ stock solution. To prepare this solution, $\mathrm{Au}(\mathrm{III})$ ions were transferred to a non-polar medium by adding an ethanol solution of tetraoctylammonium bromide $(\mathrm{TOAB})$ and toluene to a solution of $\mathrm{HAuCl}_{4} \cdot 3 \mathrm{H}_{2} \mathrm{O}$ in deionized water. $\mathrm{TOAB}$ acts as a complexing agent and assists the quantitative phase transfer of $\mathrm{Au}(\mathrm{III})$ ions to toluene, forming an orange clear solution. The Au(III)TOAB stock solution needs to be repeatedly washed with hot water in order to discard excess $\mathrm{Cl}^{-}$and $\mathrm{Br}^{-}$anions and minimize the formation of $\mathrm{AgCl}$ and $\mathrm{AgBr}$ impurities when reacting with $\mathrm{Ag}_{2} \mathrm{Se}$ NPs. Ternary $\mathrm{Ag}_{3} \mathrm{AuSe}_{2} \mathrm{NPs}$ were synthesized by simply mixing a toluene solution of $\beta-\mathrm{Ag}_{2} \mathrm{Se} \mathrm{NPs}$ and an aliquot of the $\mathrm{Au}(\mathrm{III})-\mathrm{TOAB}$ stock solution at room temperature, as indicated in Scheme $1 \mathrm{~A}$. The sample obtained is formed by spherical but slightly faceted NPs with average size close to that of the parent $\mathrm{Ag}_{2} \mathrm{Se}$ NPs, as observed by TEM and shown in Figure $\mathrm{iC}$. As depicted in Figure $1 \mathrm{D}$, the XRD analysis confirms the efficient diffusion of $\mathrm{Au}(\mathrm{I})$ ions into the $\beta-\mathrm{Ag}_{2}$ Se lattice in all the sample, and the complete phase transformation from orthorhombic to cubic symmetry. The fischesserite phase is easily identified by XRD through its most intense diffraction peak at $33^{\circ}$ assigned to the (321) set of equivalent planes, and by a peak at $12.5^{\circ}$ originating from the (110) family of planes with large interplanar distance, both characteristic of the cubic $\mathrm{Ag}_{3} \mathrm{AuSe}_{2}$ crystal structure.

A HRTEM micrograph of some NPs is shown in Figure 2. The analysis revealed that the single crystal character of the particles has been generally preserved after the reaction and that the interplanar distances measured correspond to the cubic $\mathrm{Ag}_{3} \mathrm{AuSe}_{2}$ structure as further demonstrated through image simulation. As a result of the reaction, an amorphous shell of ca. $1 \mathrm{~nm}$ thickness is observed in all NPs, whose composition and origin is discussed later for the case of the dimer-like NPs.

\section{Au-Ag2 Se and Au-Ag3AuSe2 dimer-like hybrid NPs}

In order to heterogeneously grow metallic Au domains on the surface of as-synthesized $\mathrm{Ag}_{2} \mathrm{Se} \mathrm{NPs}$, the reaction requires the presence of a mild reducing agent such as an amine. ${ }^{71}$ In the present case, dodecylamine (DDA) was used both as phase transfer and reducing agent instead of previous TOAB: a $\mathrm{Au}(\mathrm{III})$-DDA stock solution was prepared by the direct phase transfer of $\mathrm{HAuCl}_{4} \cdot 3 \mathrm{H}_{2} \mathrm{O}$ from water to toluene. ${ }^{64}$ The stock solution needs to be repeatedly washed with hot water in order to discard $\mathrm{Cl}^{-}$anions and prevent the formation of $\mathrm{AgCl}$ impurities when reacting with $\mathrm{Ag}_{2} \mathrm{Se}$ NPs. Silver chalcogenide-based semiconductor hybrid NPs containing metallic Au domains were synthesized by simply mixing a toluene solution of $\beta$ $\mathrm{Ag}_{2} \mathrm{Se}$ NPs and an aliquot of the $\mathrm{Au}(\mathrm{III})$-DDA solution at room temperature. The sample was exclusively composed of nanodimers as observed in TEM micrographs shown in Figure $3 \mathrm{~A}$, with a darker small spot in each NP, presuma-

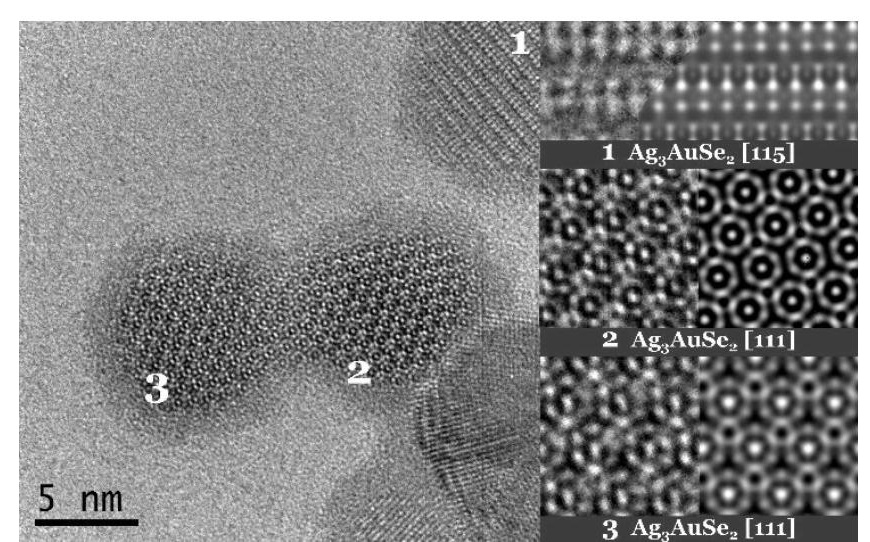


bly corresponding

Figure 2. Left: HRTEM characterization of $\mathrm{Ag}_{3} \mathrm{AuSe}_{2} \mathrm{NPs}$. Right: comparison between experimental and simulated images in the three different zone axes identified in the lefthand side panel.

to the metallic Au domain. Although the presence of $\mathrm{Au}$ could not be inferred from XRD, most probably due to the small size of the domains, ${ }^{72,73}$ the XRD spectrum shows the formation of the cubic gold(I) silver(I) selenide phase $\left(\mathrm{Ag}_{3} \mathrm{AuSe}_{2}\right)$, besides the peaks corresponding to the mixture of $\beta-\mathrm{Ag}_{2} \mathrm{Se}$ and $t-\mathrm{Ag}_{2}$ Se phases from the original NPs (results not shown). A control over the semiconductor crystalline phase is achieved by changing time of reaction and concentration of $\mathrm{Au}$ (III) ions in the stock solution. As indicated in Scheme $1 \mathrm{~B}$, a $1 \mathrm{mM} \mathrm{Au}$ (III)-DDA stock solution and 30 seconds of reaction allowed the synthesis of $\mathrm{Au}-\mathrm{Ag}_{2} \mathrm{Se}$ dimer-like hybrid NPs, thus preventing the solid
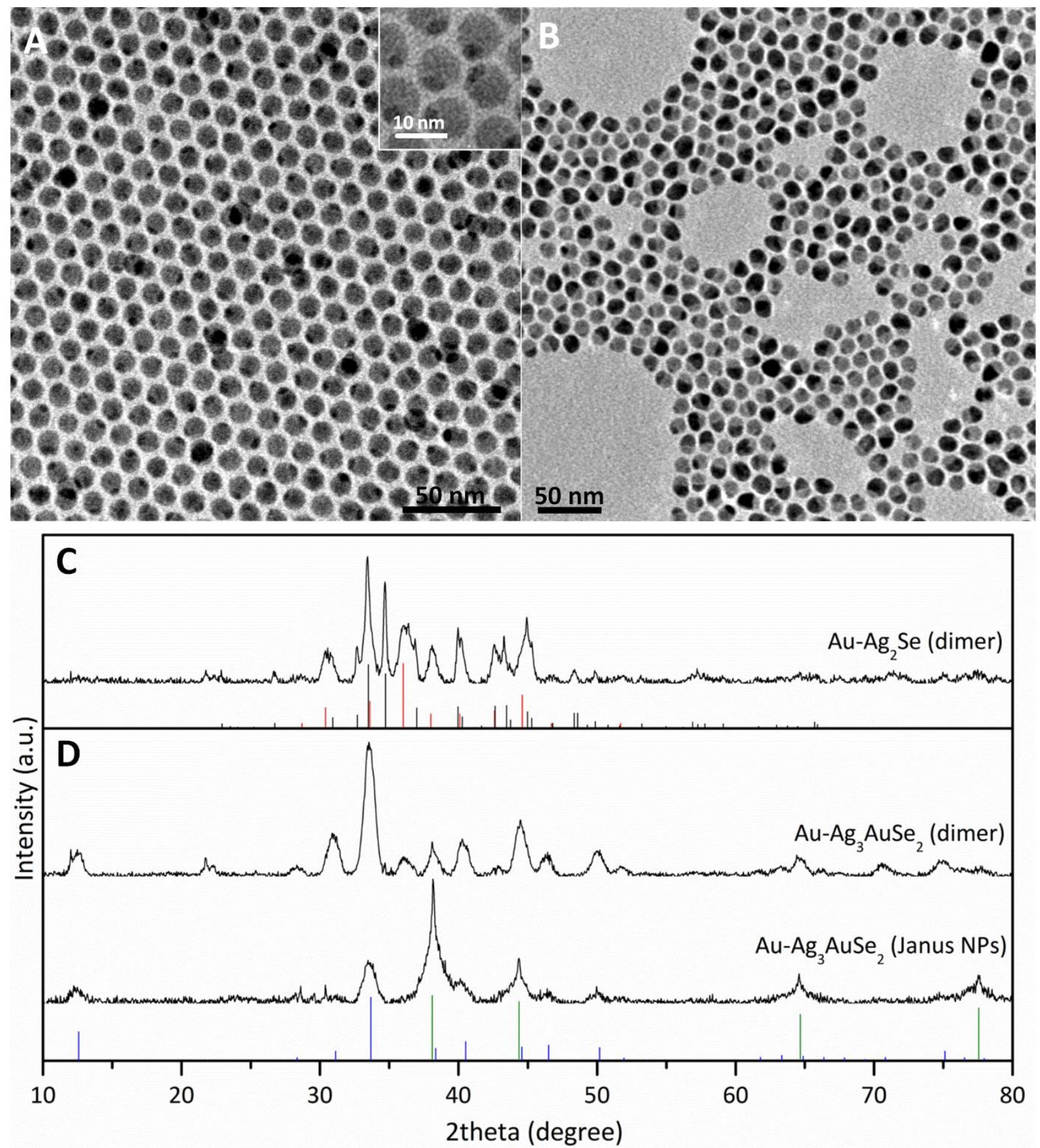

Figure 3. TEM micrographs of (A) dimer-like hybrid NPs and (B) Janus-like hybrid NPs. (C) XRD spectrum of Au-Ag $\mathrm{Se}_{2}$ hybrid $\mathrm{NPs}, \beta-\mathrm{Ag}_{2} \mathrm{Se}$ (JCPDS oo-024-1041, black) reference pattern and $t$-Ag $\mathrm{Se}_{2}$ calculated (red) pattern. ${ }^{68}$ (D) XRD spectra of Au$\mathrm{Ag}_{3} \mathrm{AuSe}_{2}$ dimer-like hybrid NPs, Au-Ag $\mathrm{AuSe}_{2}$ Janus-like hybrid NPs, $\mathrm{Ag}_{3} \mathrm{AuSe}_{2}$ (JCPDS o1-072-0392, blue) and Au (oo-002-1095, green) reference patterns. 


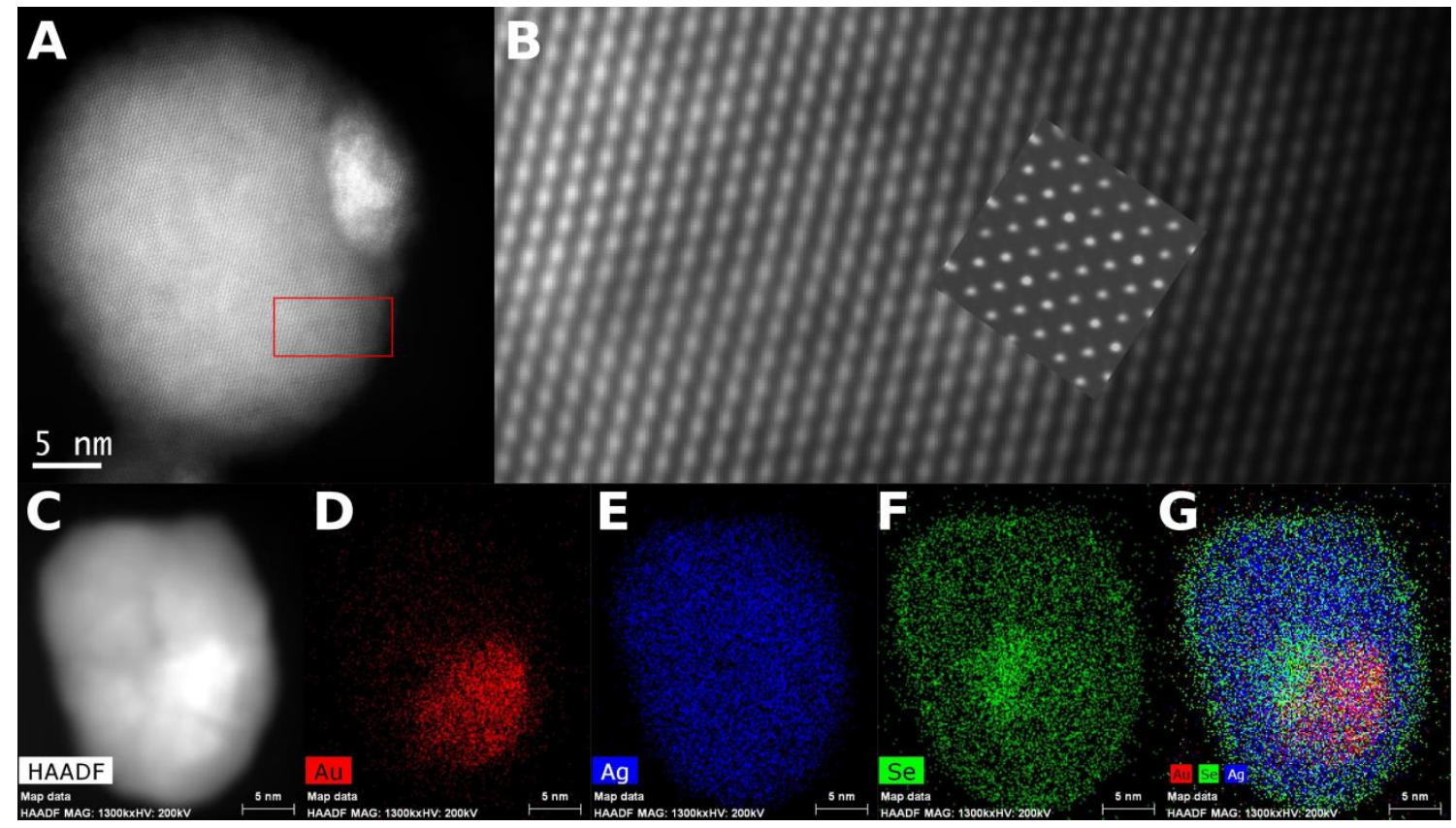

Figure 4. A) HAADF-STEM image of one of the $\mathrm{Au}-\mathrm{Ag}_{2} \mathrm{Se}$ hybrid NPs. B) Fourier filtered image from the highlighted region in A. The inset is a STEM-HAADF image simulation of $\mathrm{Ag}_{2} \mathrm{Se}$ along the [531] zone axis. C) HAAD-STEM image of another Au-Ag $\mathrm{Se}_{2}$ hybrid NP. D-F) EDX elemental maps corresponding to Au (red), Ag (blue), Se (green) respectively. G) D-F maps superimposed.

state diffusion of $\mathrm{Au}(\mathrm{I})$ ions, as deduced from XRD spectrum in Figure ${ }_{3} \mathrm{C}$. On the contrary, a more concentrated solution such as $6 \mathrm{mM}$, and longer reaction times were needed for the complete transformation of orthorhombic $\mathrm{Ag}_{2} \mathrm{Se}$ into cubic $\mathrm{Ag}_{3} \mathrm{AuSe}_{2}$ and the consequent formation of $\mathrm{Au}-\mathrm{Ag}_{3} \mathrm{AuSe}_{2}$ dimer-like hybrid NPs, as indicated in Scheme $1 \mathrm{C}$ and shown in Figure ${ }_{3} \mathrm{D}$ (dimer). In both cases the reaction is arrested by ethanol-assisted precipitation and centrifugation of the NPs and subsequent solution discard. Our experiments allow to conclude that the amine-induced reduction of $\mathrm{Au}$ (III) ions to $\mathrm{Au}^{\circ}$, and the heterogeneous nucleation and growth of the metallic domain are the fastest processes. In comparison, the partial reduction of $\mathrm{Au}(\mathrm{III})$ to $\mathrm{Au}(\mathrm{I})$ ions and the diffusion of the latter into the $\beta-\mathrm{Ag}_{2} \mathrm{Se}$ crystal lattice with the concomitant phase transformation require slightly longer times. Nonetheless, both processes take place at room temperature and with very short or moderate reaction times. This is clearly indicative of the low energy barrier associated to these processes and of the high thermodynamic stability of the newly formed fischesserite phase. Recently reported measurements of the standard Gibbs energy and enthalpy of formation of different compounds of the $\mathrm{Au}-\mathrm{Ag}-\mathrm{Se}$ ternary system indicate that the formation of bulk fischesserite is thermodynamically favored and exothermic: $\Delta \mathrm{G}_{\mathrm{f}}^{\mathrm{o}}=-86 \pm 1 \mathrm{~kJ} \mathrm{~mol}^{-1}, \Delta \mathrm{H}_{\mathrm{f}}^{\mathrm{o}}=-73 \pm$ $1 \mathrm{~kJ} \mathrm{~mol}^{-1}$. 1

The size of the metallic Au domain in the hybrid NPs can be further tuned by changing the amount of reducing
DDA in the $\mathrm{Au}(\mathrm{III})-\mathrm{DDA}$ stock solution. Thus, by adding twice the amount used in the first experiments, Au$\mathrm{Ag}_{3} \mathrm{AuSe}_{2}$ Janus-like NPs can be formed, where Au domains show average diameter similar to that of the semiconductor section, as shown in Figure ${ }_{3} \mathrm{~B}$. The increase in size of the metallic domain in the latter sample allows the observation of the characteristic reflections of cubic $\mathrm{Au}$ in the XRD spectrum shown in Figure $3 \mathrm{D}$ (Janus NPs), as well as its very well-known surface plasmon resonance (SPR) mode in the UV-visible absorption spectrum, as shown in Figure $\mathrm{S}_{4}$.

High angle annular dark field-Scanning TEM (HAADFSTEM) and energy dispersive X-ray spectroscopy (EDX) techniques have been used for an in-depth structural and chemical characterization of the $\mathrm{Au}-\mathrm{Ag}_{2} \mathrm{Se}$ hybrid NPs. Figure 4A shows a HAADF-STEM image of a typical dimer NP. The higher intensity at the small domain suggests that this corresponds to metallic Au as expected. This is further confirmed by HRTEM images of dimers depicted in Figure $\mathrm{S}_{5}$, where the $d$-spacing values observed in the small higher intensity areas clearly correspond to $f_{c c} \mathrm{Au}$. A detailed interface analysis suggests that the two domains are not related by any specific epitaxy and that the two crystalline lattices are randomly oriented in the nanostructures. In Figure $4 \mathrm{~B}$, a Fourier filtered image of the crystal shows a good match with a simulated HAADF image of $\beta-\mathrm{Ag}_{2} \mathrm{Se}$. This confirms that the crystalline structure of the large domain clearly corresponds to that of the orthorhombic $\mathrm{Ag}_{2} \mathrm{Se}$. EDX elemental mapping per- 
formed on the dimer NP displayed in Figure ${ }_{4} \mathrm{C}$ shows the spatial distribution of $\mathrm{Au}, \mathrm{Ag}$ and Se elements in the structure (Figure ${ }_{4} \mathrm{D}-\mathrm{G}$ ). The qualitative and quantitative analyses performed evidence that the large domain is made of binary $\mathrm{Ag}_{2} \mathrm{Se}$ and confirm the $2 \mathrm{Ag}$ :Se stoichiometry expected. On the other hand, the analysis suggests that $\mathrm{Au}$ is located almost exclusively at the small domain. Although some degree of diffusion of $\mathrm{Au}(\mathrm{I})$ into the $\beta$ $\mathrm{Ag}_{2} \mathrm{Se}$ structure cannot be totally excluded, this value remains very low, if any.

For comparison purposes, $\mathrm{Au}-\mathrm{Ag}_{3} \mathrm{AuSe}_{2}$ dimer-like hybrid NPs were also structurally and chemically characterized. Figure 5 A shows a HAADF-STEM image of a typical dimer NP. As in the previous case, the higher intensity at the small domain suggests that this corresponds to metallic $\mathrm{Au}$. Interplanar distances corresponding to both cubic $\mathrm{Ag}_{3} \mathrm{AuSe}_{2}$ and metallic Au were identified in the dimers by HRTEM as illustrated in Figures S6 and S7. The analysis of the images suggests that the two domains do not follow any specific epitaxy. Figure ${ }^{\mathrm{B}}$ shows a STEM-HAADF image simulation of fischesserite in the [111] zone axis. A zoom of a region that belongs to the upper domain of the experimental image in $5 \mathrm{~A}$ is shown in Figure ${ }_{5} \mathrm{C}$. The latter has been rotated and its contrast adjusted for comparison with the simulation in $5 \mathrm{~B}$. As observed, both simulated and experimental images follow the same structural pattern and symmetry and one can be seen as the natural continuity of the other. Likewise, in Figure S8 a fischesserite crystalline structure model seen along the [111] zone axis has been superimposed to the STEM-HAADF image of the $\mathrm{Ag}_{3} \mathrm{AuSe}_{2}$ domain oriented along the same zone axis, coinciding to a large extent. Thus, the images confirm that the initial $\beta-\mathrm{Ag}_{2} \mathrm{Se}$ crystalline structure has been fully transformed into a new structure with cubic symmetry corresponding to $\mathrm{Ag}_{3} \mathrm{AuSe}_{2}$. Electron energy loss (EEL) spectra were recorded on the dimer NP displayed in Figure $5 \mathrm{~A}$ in order to confirm the new expected chemical distribution. The corresponding chemical mappings for $\mathrm{Au}$ and Se are shown in Figure $5 \mathrm{D}-\mathrm{F}$. The images exhibit that $\mathrm{Au}$ is largely distributed all through the particle, with a higher density on the region that belongs to the metallic domain. The Se:Au atomic ratio is close to 2, as obtained from quantification ${ }^{74}$ of the spectra recorded along the semiconductor section, in agreement with the value expected from a $\mathrm{Ag}_{3} \mathrm{AuSe}_{2}$ stoichiometry. Additional EELS measurements were performed for a different hybrid NP of the same sample in order to figure out the relative abundance of $\mathrm{Ag}$ and Se in the dimeric structures. The corresponding chemical mappings are shown in Figure S9. The results indicate the homogeneous distribution of the two species in the inner core and the formation of an amorphous outer shell of $c a .1 \mathrm{~nm}$ thickness containing mainly Se, as observed in Figure S9 when the signals for Se and Ag are superimposed. This shell is analogous to that observed after the formation of single crystal $\mathrm{Ag}_{3} \mathrm{AuSe}_{2} \mathrm{NPs}$. The measured Ag:Se ratio is close to unity, and consequently slightly lower than the theoretical one for $\mathrm{Ag}_{3} \mathrm{AuSe}_{2}$, most likely due to the thin Se-rich coverage.
X-ray photoelectron spectroscopy (XPS) confirms the presence of $\operatorname{Ag}(\mathrm{I})$ and $\mathrm{Au}(\mathrm{I})$ species in the sample for which a Ag:Au ratio of 3 could be inferred in agreement with all previous results, as depicted in Figure Sio. Surprisingly, $\mathrm{Au}(\mathrm{o})$ species were not detected in the XPS measurements performed. Nonetheless, and considering the surface-sensitive character of this technique, it seems reasonable to assume that the presence of a non-metallic shell might be the reason for the quenching of the

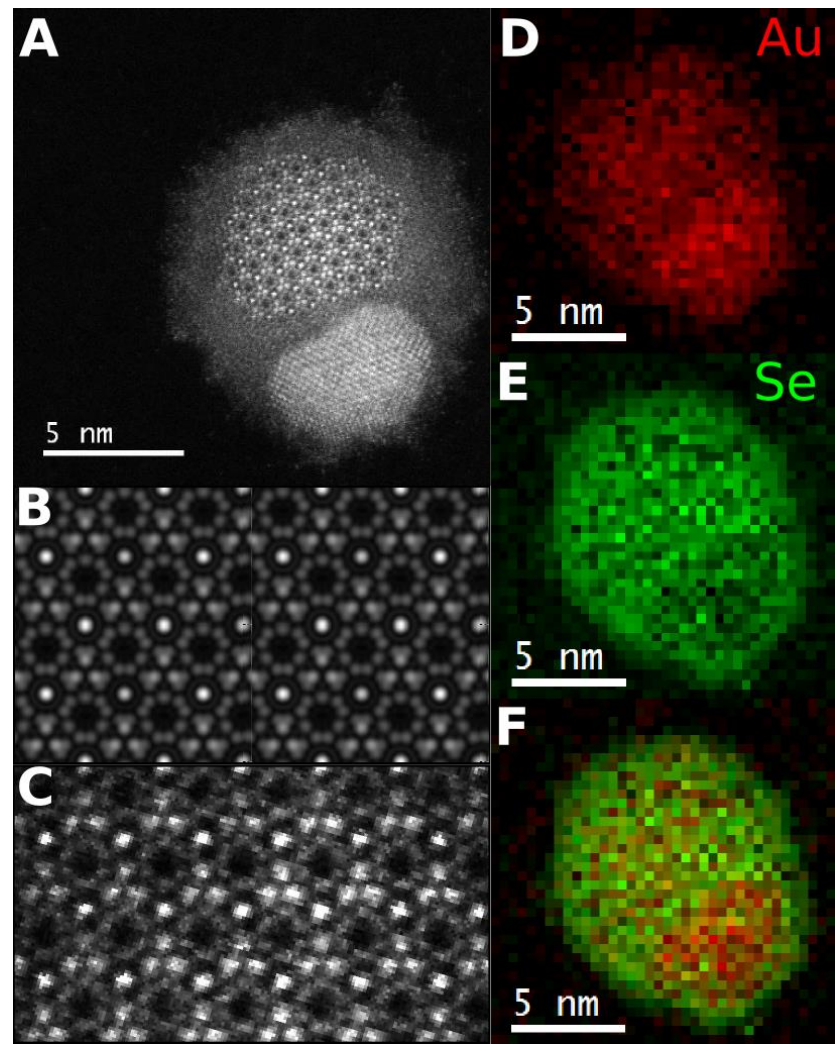

Figure 5. A) STEM-HAADF image of a single $\mathrm{Au}-\mathrm{Ag}_{3} \mathrm{AuSe}_{2}$ dimer-like hybrid NP. B) STEM-HAADF image simulation of fischesserite in the [111] zone axis. C) Zoom of a region from A. Image has been rotated and contrast adjusted for comparison with the simulation in $\mathrm{B}$. D) EELS Au signal from the particle in A. E) EELS Se signal from the particle in A. F) D and E superposition.

XPS Au(o) signal. All in all, these results are generally consistent with the formation of the fischesserite phase in the dimers.

The full reduction of $\mathrm{Au}(\mathrm{III})$ ions to metallic $\mathrm{Au}$ and the consequent formation of hybrid NPs occur exclusively in the presence of an aliphatic amine in the reaction medium, i.e. DDA. This is in total agreement with the previously observed reducing character of long chain amines, and with their well-known ability to form noble metal NPs both homogeneously and heterogeneously in solution using metal salts as precursors. ${ }^{14,71}$ On the other hand, our experiments indicate that the presence of an 
amine in the reaction medium is not necessary for the formation of $\mathrm{Ag}_{3} \mathrm{AuSe}_{2} \mathrm{NPs}$ or nanodomains, since these are formed also when using only TOAB as surfactant. TOAB, being this surfactant formed by a quaternary ammonium cation without non-bonding electron pairs, is unable to perform as a reducing agent, contrary to a pri- mary amine like DDA. Thus, there must be another chemical specie acting as reducing agent, which must be strong enough so as to reduce $\mathrm{Au}(\mathrm{III})$ to $\mathrm{Au}(\mathrm{I})$ ions allowing the formation of fischesserite domains, but also weak enough so as to prevent the full reduction of $\mathrm{Au}$ ions
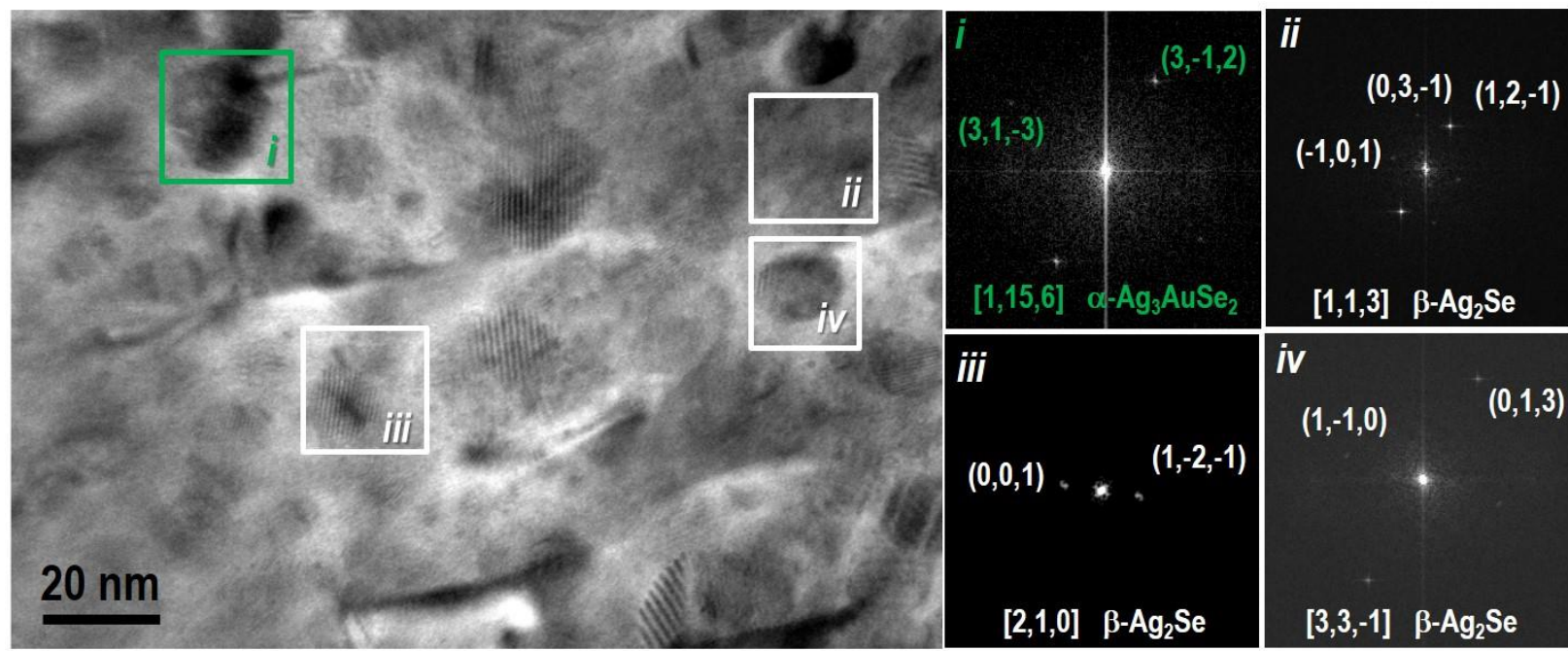

Figure 6. HRTEM image and FFT analysis of the Ag-Au-Se nanocomposite pellet.
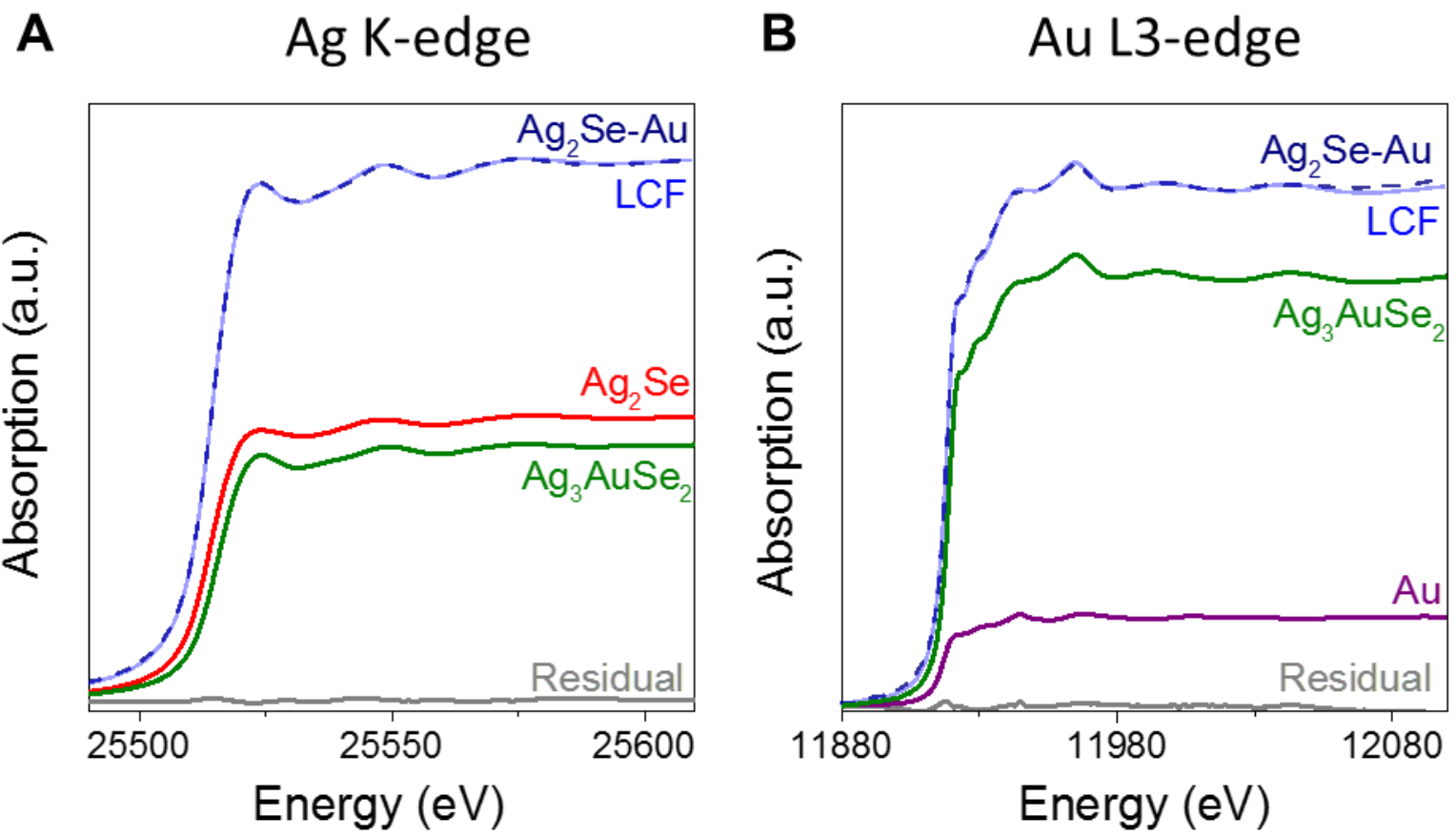

Figure 7. Linear combination fit of XANES of the Ag-Au-Se nanocomposite pellet at (A) Ag K-edge and (B) Au $\mathrm{L}_{3}$-edge. In green the weighted $\mathrm{Ag}_{3} \mathrm{AuSe}_{2}$ spectra, in purple the weighted metallic Au and in red the weighted $\mathrm{Ag}_{2} \mathrm{Se} \mathrm{NP}$ spectra, contributing to the fit of the Ag-Au-Se nanocomposite spectra.

to form metallic Au crystals. As explained before, the formation of the ternary $\mathrm{Ag}_{3} \mathrm{AuSe}_{2}$ domains, either as single crystal or hybrid NPs, is accompanied by the formation of a Se-rich amorphous shell of ca. $1 \mathrm{~nm}$ thickness (see Figures 2 and 5 and Figures $\mathrm{S}_{7}$ and $\mathrm{S}_{9}$ ). The latter is not observed in the $\mathrm{Ag}_{2} \mathrm{Se}$-precursor NPs that show excel- lent crystallinity (see Figure S2), and hence it can be concluded that it forms only as a result of the reaction with an $\mathrm{Au}(\mathrm{III})$ precursor, either $\mathrm{Au}(\mathrm{III})-\mathrm{TOAB}$ or $\mathrm{Au}(\mathrm{III})$ DDA. Based on these evidences, we suggest the following mechanism as the most plausible explanation for the formation of the ternary fischesserite phase: first, $\mathrm{Au}(\mathrm{III})$ 
ions are reduced to $\mathrm{Au}(\mathrm{I})$ by oxidizing the most external layers of $\mathrm{Ag}_{2} \mathrm{Se} \mathrm{NPs}$, which act as a sacrificial shell forming elemental amorphous Se (eq 1). Next, the newly formed $\mathrm{Au}(\mathrm{I})$ ions suffer a solid state diffusion through the underlying $\beta$ - $\mathrm{Ag}_{2} \mathrm{Se}$ lattice (core) simultaneously exchanging one fourth of its $\mathrm{Ag}(\mathrm{I})$ ions, and leading to the formation of the ternary phase (eq 2). The same reactions are expected to take place when using either $\mathrm{Au}(\mathrm{III})$ TOAB or $\mathrm{Au}(\mathrm{III})$-DDA stock solutions as precursors, although the partial $\mathrm{Au}(\mathrm{III})$ to $\mathrm{Au}(\mathrm{I})$ reduction competes with the faster $\mathrm{Au}(\mathrm{III})$ to metallic Au reduction in the second case.

(1)

$$
\left[\mathrm{Ag}_{2} \mathrm{Se}\right]_{\text {shell }}+\mathrm{Au}(\mathrm{III}) \longrightarrow[\mathrm{Se}]_{\text {shell }}+\mathrm{Au}(\mathrm{I})+2 \mathrm{Ag}(\mathrm{I})
$$

(2)

${ }_{2}\left[\mathrm{Ag}_{2} \mathrm{Se}\right]_{\text {core }}+\mathrm{Au}(\mathrm{I}) \longrightarrow\left[\mathrm{Ag}_{3} \mathrm{AuSe}_{2}\right]_{\text {core }}+\mathrm{Ag}(\mathrm{I})$

Both the oxidation of $\mathrm{Ag}_{2} \mathrm{Se}$ to Se and the cation exchange reaction are accompanied by the release of $\mathrm{Ag}(\mathrm{I})$ ions to the solution that precipitate in the form of $\mathrm{AgBr}$. In fact, microcrystalline $\mathrm{AgBr}$ impurities are observed in the XRD spectrum when the sample is not appropriately cleaned.

\section{Thermoelectric characterization}

In order to evaluate the thermoelectric properties of the $\mathrm{Ag}-\mathrm{Au}$-Se nanocomposite system, roughly $0.5 \mathrm{~g}$ of each type of $\mathrm{Ag}_{2} \mathrm{Se}$ and $\mathrm{Au}-\mathrm{Ag}_{2} \mathrm{Se}$ NPs were prepared and homogeneously mixed in solution. The mixed NPs were thoroughly washed by multiple precipitation and redispersion steps. Washed NPs were dried under vacuum to obtain a dark gray nanopowder. To remove completely the residual organic ligands, NPs were heated at $450{ }^{\circ} \mathrm{C}$ for $1 \mathrm{~h}$ under an argon flow. The annealed nanopowder was ground and hot-pressed under an Ar atmosphere at $\sim 40 \mathrm{MPa}$ and $400{ }^{\circ} \mathrm{C}$ during 4 minutes. The obtained $\mathrm{Ag}$ $\mathrm{Au}$-Se nanocomposite pellet was silver-metallic in appearance and had a relative density of $92 \%$. An analogous pellet was prepared with $1 \mathrm{~g}$ of only binary $\mathrm{Ag}_{2} \mathrm{Se} \mathrm{NPs}$, to be used as a reference material in the thermoelectric studies.

An exhaustive characterization of the annealing and consolidation effect was challenging but also necessary to understand the thermoelectric performance of the obtained Ag-Au-Se nanocomposite. As proven by Field Emission Scanning Electron Microscopy (FESEM) (Figure Si1) and EDX analysis, the morphology and chemical composition of the final ternary nanocomposite was highly homogeneous at the micrometer scale but contained a uniform distribution of compositional inhomogeneities at the nanometer scale. HRTEM analysis of thin slices prepared by focused ion beam of the Ag-Au-Se nanocomposite pellet showed the presence of $\mathrm{Ag}_{2} \mathrm{Se}$ and $\mathrm{Ag}_{3} \mathrm{AuSe}_{2}$ crystal nanodomains with sizes in the range $5-20 \mathrm{~nm}$ as indicated in Figure 6. Metallic Au domains were not detected in the HRTEM images.

In order to perform a full chemical characterization of the $\mathrm{Ag}-\mathrm{Au}-\mathrm{Se}$ nanocomposite and to identify every phase present in the ternary pellet, we performed X-ray absorption spectroscopy (XAS) and the results are shown in Figure 7 (see also SI for further details on results and fitting conditions). After annealing and consolidation of the NPs mixture, we could observe how part of the initial metallic Au converted into $\mathrm{Ag}_{3} \mathrm{AuSe}_{2}$ in the final pellet. Linear combination fitting of the X-ray absorption near edge structure (XANES) around the $\mathrm{Au}$ absorption $\mathrm{L}_{3}$ edge, using references of $\mathrm{Ag}_{3} \mathrm{AuSe}_{2}$ and $\mathrm{Au} \mathrm{NPs}$, confirmed that approximately $58 \%$ of the Au species are in the form of metallic Au and $42 \%$ in the form of the ternary $\mathrm{Ag}_{3} \mathrm{AuSe}_{2}$ phase. Hence, although we could not find metallic $\mathrm{Au}$ in the HRTEM study, XAS analysis verified the presence of three different phases i) $\mathrm{Ag}_{2} \mathrm{Se}$, ii) $\mathrm{Ag}_{3} \mathrm{AuSe}_{2}$, and iii) $\mathrm{Au}$ in the Ag-Au-Se nanocomposite.

Figure $\mathrm{S}_{12}$ displays the XRD spectra of both the Ag-Au-Se nanocomposite and $\mathrm{Ag}_{2} \mathrm{Se}$ reference nanocomposite. After the annealing treatment, reflections become narrower in both cases, indicating an increase of the average crystal size.

Figure 8 shows the electrical conductivity $(\sigma)$, Seebeck coefficient $(S)$, thermal conductivity $(\kappa)$ and final figure of merit $\left(Z T=\sigma S^{2} \kappa^{-1}\right)$ for the pellets with the Ag-Au-Se ternary nanocomposite and the $\mathrm{Ag}_{2}$ Se reference binary system. The best thermoelectric performance was found to be around $390 \mathrm{~K}$. Both samples presented a pronounced change of the thermoelectric properties at ca. $400 \mathrm{~K}$, which is associated with the phase transition from the low temperature orthorhombic $\beta-\mathrm{Ag}_{2} \mathrm{Se}$ to the high temperature cubic $\alpha-\mathrm{Ag}_{2} \mathrm{Se}$ phase. ${ }^{5^{\circ}}$ The atomic rearrangement to $\alpha-\mathrm{Ag}_{2} \mathrm{Se}$ is characterized by dynamic disorder of $\mathrm{Ag}^{+}$ions within an immobile anion sublattice. ${ }^{75,76}$ $\alpha-\mathrm{Ag}_{2} \mathrm{Se}$ high ionic conductivity resulted in slightly higher electrical conductivities due to the contribution of the $\mathrm{Ag}^{+}$charge carriers. However, this had a detrimental effect on the Seebeck coefficient due to the contribution of p-type $\mathrm{Ag}^{+}$charge carriers in n-type $\mathrm{Ag}_{2} \mathrm{Se}$. Two-fold lower electrical conductivities, but 50\% higher Seebeck coefficients were obtained in the Ag-Au-Se system when compared to the bare $\mathrm{Ag}_{2} \mathrm{Se}$ nanomaterial, what translated into higher power factors. We associated this behavior to a charge scattering and corresponding energy filtering of carriers with lower energy, hence reducing the bipolar effect induced by the phase transition. Additionally, the presence of $\mathrm{Au}$ and $\mathrm{Ag}_{3} \mathrm{AuSe}_{2}$ resulted in a strong decrease of the thermal conductivity due to the more efficient scattering of phonons at the grain boundaries enhanced by the acoustic impedance mismatch of $\mathrm{Ag}_{2} \mathrm{Se}, \mathrm{Au}$ and $\mathrm{Ag}_{3} \mathrm{AuSe}_{2}$ domains. Overall, a 7 fold increase in the thermoelectric figure of merit, from $Z T=0.12$ for pure $\mathrm{Ag}_{2} \mathrm{Se}$ reference system to $Z T=0.88$ for the Ag-Au-Se nanocomposites at $390 \mathrm{~K}$ was obtained. 


\section{CONCLUSIONS}

The synthetic possibilities of the Ag-Au-Se ternary system have been investigated by means of wet chemistry techniques, and $\mathrm{Ag}_{3} \mathrm{AuSe}_{2}$ ternary NPs as well as $\mathrm{Au}-\mathrm{Ag}_{2} \mathrm{Se}$ and $\mathrm{Au}-\mathrm{Ag}_{3} \mathrm{AuSe}_{2}$ hybrid nanostructures have been successfully prepared at room temperature under different reaction conditions, starting from pre-made $\mathrm{Ag}_{2} \mathrm{Se} \mathrm{NPs}$. The detailed characterization performed confirmed the
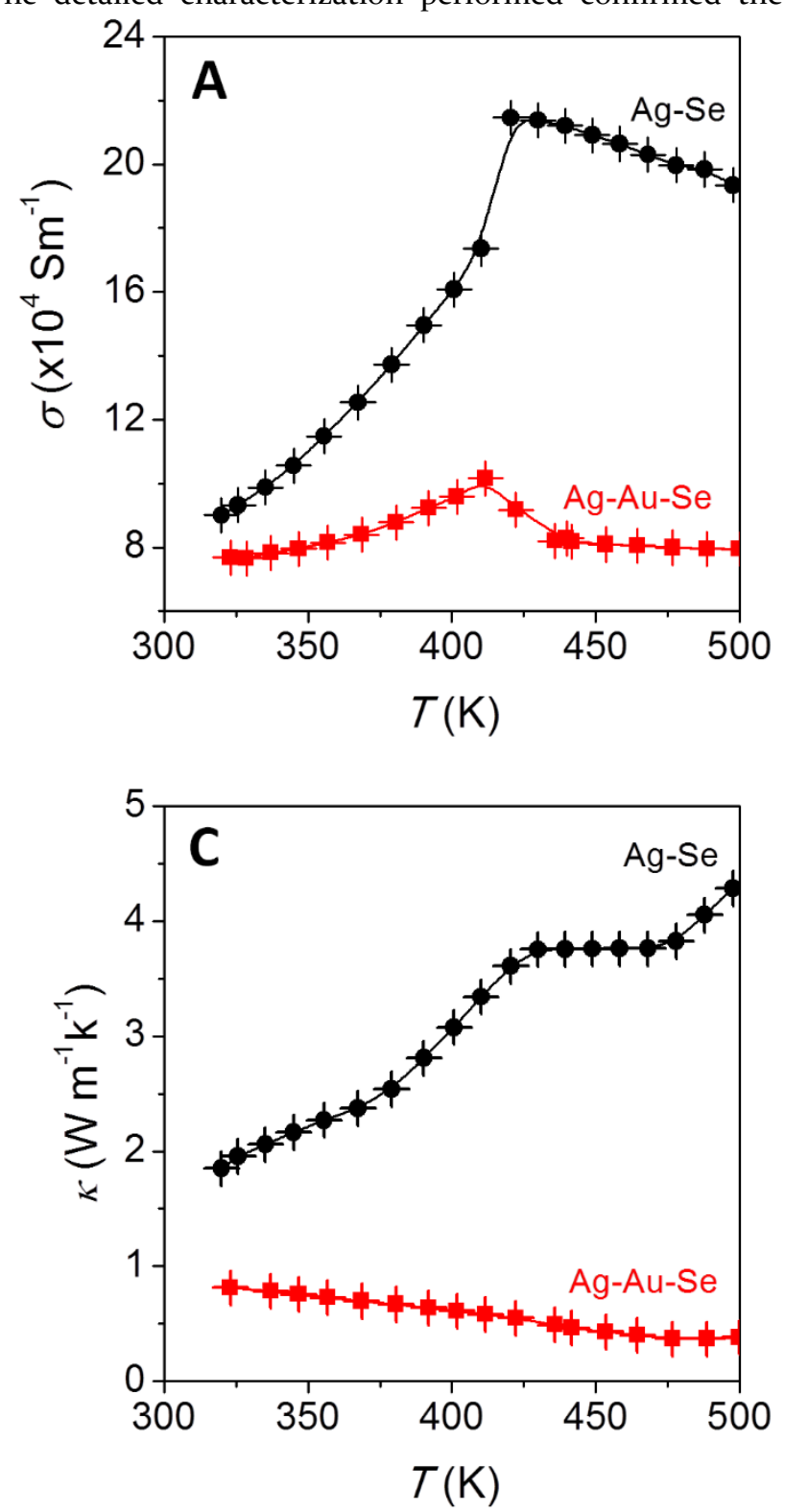

high homogeneity of the samples, and evidenced the high versatility offered by the method in order to tune the binary, ternary and hybrid character of the NPs as desired. Remarkably, the rare ternary $\mathrm{Ag}_{3} \mathrm{AuSe}_{2}$ fischesserite phase has been prepared and structurally and chemically characterized at the nanoscale. The thermal and electric properties of a Ag-Au-Se ternary nanocomposite have been

stud
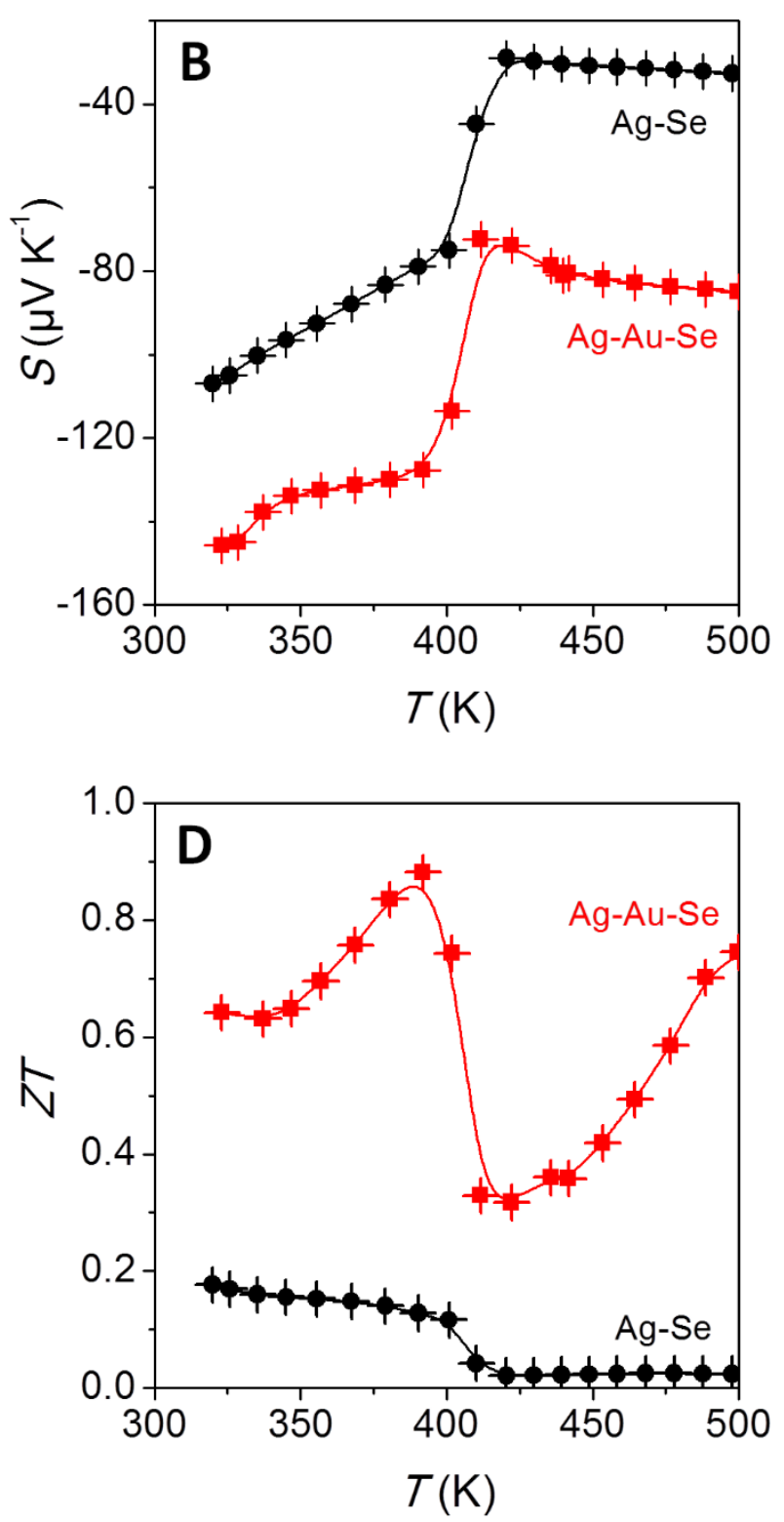

Figure 8. (A) Electrical conductivity, (B) Seebeck coefficient, (C) thermal conductivity, and (D) figure of merit of Ag ${ }_{2} \mathrm{Se}_{\mathrm{refer}}$ ence system and $\mathrm{Ag}$-Au-Se ternary nanocomposite.

ied in order to explore the potential of this system for thermoelectric energy conversion. The results indicate that the occurrence of metallic $\mathrm{Au}$ and $\mathrm{Ag}_{3} \mathrm{AuSe}_{2}$ phases within a $\mathrm{Ag}_{2} \mathrm{Se}$ matrix in the nanocomposite induces a 7 fold increase in the thermoelectric figure of merit compared with that obtained for the binary Ag-Se analogue. Overall, our work highlights the effectiveness of colloidal chemistry to design new nano-building blocks for the fabrication of functional nanocomposites with optimized properties.

\section{ASSOCIATED CONTENT}

TEM, HRTEM and XRD characterization of $\mathrm{Ag}_{2} \mathrm{Se}$ NPs. UVVis absorption spectra and HRTEM studies of $\mathrm{Ag}_{2} \mathrm{Se}$-based nanostructured materials. Structural and chemical analysis of hybrid NPs by HRTEM, HAADF-STEM, EELS and XPS. Mor- 
phological and structural characterization of the Ag-Au-Se nanocomposite pellet by FESEM and XRD. Results and fitting conditions of the linear combination fitting of XAS spectra. This material is available free of charge via the Internet at http://pubs.acs.org.

\section{AUTHOR INFORMATION}

\section{Corresponding Author}

*E-mail: albert.figuerola@qi.ub.es

\section{Notes}

The authors declare no competing financial interests.

\section{ACKNOWLEDGMENT}

We acknowledge financial support from the Spanish MINECO through CTQ2012-32247, CTQ2015-68370-P and ENE2015-63969-R, and from the Generalitat de Catalunya through 2014 SGR 129. A. F. acknowledges the Spanish MINECO for a Ramón y Cajal Fellowship (RYC-2010-05821). J.L. is Serra Húnter Fellow and is grateful to ICREA Academia program. At IREC, work was supported by European Regional Development Funds and the Framework 7 program under project UNION (FP7-NMP 310250). M.I. thanks AGAUR for their Beatriu de Pinós post-doctoral grant. M. V. K. acknowledges partial financial support by the European Union (EU) via $\mathrm{FP}_{7}$ ERC Starting Grant 2012 (Project NANOSOLID, GA No. 306733). L.P. acknowledges support from the Scholarship Fund of the Swiss Chemical Industry (SSCI). The Swiss Light Source is thanked for the provision of beamtime at the SuperXAS beamline.

\section{REFERENCES}

(1) Li, C.; Han, X.; Cheng, F.; Hu, Y.; Chen, C.; Chen, J. Phase and Composition Controllable Synthesis of Cobalt Manganese Spinel Nanoparticles towards Efficient Oxygen Electrocatalysis. Nat. Commun. 2015, 6, 7345.

(2) Zeng, H. C. Integrated Nanocatalysts. Acc. Chem. Res. 2013 46, 226-235.

Barkhouse, D. A. R.; Debnath, R.; Kramer, I. J.; Zhitomirsky, D.; Pattantyus-Abraham, A. G.; Levina, L.; Etgar, L.; Grätzel, M.; Sargent, E. H. Depleted Bulk Heterojunction Colloidal Quantum Dot Photovoltaics. Adv. Mater. 2011, 23, 31343138.

(4) Kramer, I. J.; Sargent, E. H. The Architecture of Colloidal Quantum Dot Solar Cells: Materials to Devices. Chem. Rev. 2014, 114, 863-882.

(5) Dang, C.; Lee, J.; Zhang, Y.; Han, J.; Breen, C.; Steckel, J. S.; Coe-Sullivan, S.; Nurmikko, A. A Wafer-Level Integrated White-Light-Emitting Diode Incorporating Colloidal Quantum Dots as a Nanocomposite Luminescent Material. Adv. Mater. 2012, 24, 5915-5918.

Yu, B.; Zebarjadi, M.; Wang, H.; Lukas, K.; Wang, H.; Wang, D.; Opeil, C.; Dresselhaus, M.; Chen, G.; Ren, Z. Enhancement of Thermoelectric Properties by ModulationDoping in Silicon Germanium Alloy Nanocomposites. Nano Lett. 2012, 12, 2077-2082.

Biswas, K.; He, J.; Blum, I. D.; Wu, C.-I.; Hogan, T. P.; Seidman, D. N.; Dravid, V. P.; Kanatzidis, M. G. HighPerformance Bulk Thermoelectrics with All-Scale Hierarchical Architectures. Nature 2012, 489, 414-418.
Boundaries for High-Performance Bulk Thermoelectrics. Science 2015, 348, 109-114.

Heremans, J. P.; Jovovic, V.; Toberer, E. S.; Saramat, A.; Kurosaki, K.; Charoenphakdee, A.; Yamanaka, S.; Snyder, G. J. Enhancement of Thermoelectric Efficiency in PbTe by Distortion of the Electronic Density of States. Science 20o8, 321, 1457-1461.

Bahk, J. H.; Bian, Z.; Shakouri, A. Electron Energy Filtering by a Nonplanar Potential to Enhance the Thermoelectric Power Factor in Bulk Materials. Phys. Rev. B - Condens. Matter Mater. Phys. 2013, 87, 075204.

(11) Ibáñez, M.; Luo, Z.; Genç, A.; Piveteau, L.; Ortega, S.; Cadavid, D.; Dobrozhan, O.; Liu, Y.; Nachtegaal, M.; Zebarjadi, M.; et al. High-Performance Thermoelectric Nanocomposites from Nanocrystal Building Blocks. Nat. Commun. 2016, 7, 10766.

(12) Zhang, Y.; Stucky, G. D. Heterostructured Approaches to Efficient Thermoelectric Materials. Chem. Mater. 2014, 26, 837-848.

(13) Zhao, L. D.; Hao, S.; Lo, S. H.; Wu, C. I.; Zhou, X.; Lee, Y.; Li, H.; Biswas, K.; Hogan, T. P.; Uher, C.; et al. High Thermoelectric Performance via Hierarchical Compositionally Alloyed Nanostructures. J. Am. Chem. Soc. 2013, 135, 7364-7370.

(14) Mokari, T.; Rothenberg, E.; Popov, I.; Costi, R.; Banin, U. Selective Growth of Metal Tips onto Semiconductor Quantum Rods and Tetrapods. Science 2004, 304, 17871790.

(15) Shi, W.; Zeng, H.; Sahoo, Y.; Ohulchanskyy, T. Y.; Ding, Y.; Wang, Z. L.; Swihart, M.; Prasad, P. N. A General Approach to Binary and Ternary Hybrid Nanocrystals. Nano Lett. 2006, 6, 875-881.

(16) Costi, R.; Saunders, A. E.; Banin, U. Colloidal Hybrid Nanostructures: A New Type of Functional Materials. Angew. Chemie - Int. Ed. 2010, 49, 4878-4897.

(17) Fernàndez-Altable, V.; Dalmases, M.; Falqui, A.; Casu, A.; Torruella, P.; Estradé, S.; Peiró, F.; Figuerola, A. Au-Assisted Growth of Anisotropic and Epitaxial CdSe Colloidal Nanocrystals via in Situ Dismantling of Quantum Dots. Chem. Mater. 2015, 27, 1656-1664.

(18) Prusty, G.; Guria, A. K.; Mondal, I.; Dutta, A.; Pal, U.; Pradhan, N. Modulated Binary-Ternary Dual Semiconductor Heterostructures. Angew. Chemie Int. Ed. 2016, 55, 2705-2708.

(19) Robinson, R. D.; Sadtler, B.; Demchenko, D. O.; Erdonmez, C. K.; Wang, L.-W.; Alivisatos, A. P. Spontaneous Superlattice Formation in Nanorods through Partial Cation Exchange. Science 2007, 317, 355-358.

(20) Li, H.; Zanella, M.; Genovese, A.; Povia, M.; Falqui, A.; Giannini, C.; Manna, L. Sequential Cation Exchange in Nanocrystals: Preservation of Crystal Phase and Formation of Metastable Phases. Nano Lett. 2011, 11, 4964-4970.

(21) Deng, Z.; Han, D.; Liu, Y. Colloidal Synthesis of Metastable Zinc-Blende IV-VI SnS Nanocrystals with Tunable Sizes. Nanoscale 2011, 3, 4346-4351.

(22) Baranov, A. N.; Sokolov, P. S.; Tafeenko, V. A.; Lathe, C.; Zubavichus, Y. V.; Veligzhanin, A. A.; Chukichev, M. V.; Solozhenko, V. L. Nanocrystallinity as a Route to Metastable Phases: Rock Salt ZnO. Chem. Mater. 2013, 25, 1775-1782.

(23) Powell, A. E.; Hodges, J. M.; Schaak, R. E. Preserving Both Anion and Cation Sublattice Features during a Nanocrystal 
Cation Exchange Reaction: Synthesis of Metastable Wurtzite-Type CoS and MnS. J. Am. Chem. Soc. 2016, 138, 471-474.

(24) Cozzoli, P. D.; Pellegrino, T.; Manna, L. Synthesis, Properties and Perspectives of Hybrid Nanocrystal Structures. Chem. Soc. Rev. 2006, 35, 1195-1208.

(25) Kovalenko, M. V; Manna, L.; Cabot, A.; Hens, Z.; Talapin, D. V; Kagan, C. R.; Klimov, X. V. I.; Rogach, A. L.; Reiss, P.; Milliron, D. J.; et al. Prospects of Nanoscience with Nanocrystals. ACS Nano 2015, 9, 1012-1057.

(26) Zhong, H.; Zhou, Y.; Yang, Y.; Yang, C.; Li, Y. Synthesis of Type II CdTe-CdSe Nanocrystal Heterostructured MultipleBranched Rods and Their Photovoltaic Applications. J. Phys. Chem. C 2007, 111, 6538-6543.

(27) Li, Y.; Mastria, R.; Fiore, A.; Nobile, C.; Yin, L.; Biasiucci, M.; Cheng, G.; Cucolo, A. M.; Cingolani, R.; Manna, L.; et al. Improved Photovoltaic Performance of Heterostructured Tetrapod-Shaped CdSe/CdTe Nanocrystals Using C6o Interlayer. Adv. Mater. 2009, 21, 4461-4466.

(28) Costi, R.; Saunders, A. E.; Elmalem, E.; Salant, A.; Banin, U. Visible Light-Induced Charge Retention and Photocatalysis with Hybrid CdSe-Au Nanodumbbells. Nano Lett. 2008, 8, 637-641.

(29) Elmalem, E.; Saunders, A. E.; Costi, R.; Salant, A.; Banin, U. Growth of Photocatalytic CdSe-Pt Nanorods and Nanonets. Adv. Mater. 2008, 20, 4312-4317.

(30) Ibáñez, M.; Zamani, R.; Gorsse, S.; Fan, J.; Ortega, S.; Cadavid, D.; Morante, J. R.; Arbiol, J.; Cabot, A. Core-Shell Nanoparticles As Building Blocks for the Bottom-Up Production of Functional Nanocomposites: PbTe-PbS Thermoelectric Properties. ACS Nano 2013, 7, 2573-2586.

（31） Jiang, G.; Zhu, H.; Zhang, X.; Shen, B.; Wu, L.; Zhang, S.; Lu, G.; Wu, Z.; Sun, S. Core/Shell Face-Centered Tetragonal FePd/Pd Nanoparticles as an Efficient Non-Pt Catalyst for the Oxygen. ACS Nano 2015, 9, 11014-11022.

(32) Yu, X.; Shavel, A.; An, X.; Luo, Z.; Ibáñez, M.; Cabot, A. $\mathrm{Cu}_{2} \mathrm{ZnSnS}_{4}-\mathrm{Pt}$ and $\mathrm{Cu}_{2} \mathrm{ZnSnS}_{4}-\mathrm{Au}$ Heterostructured Nanoparticles for Photocatalytic Water Splitting and Pollutant Degradation. J. Am. Chem. Soc. 2014, 136, 92369239.

(33) Nafria, R.; Genç, A.; Ibáñez, M.; Arbiol, J.; Ramírez de la Piscina, P.; Homs, N.; Cabot, A. Co-Cu Nanoparticles: Synthesis by Galvanic Replacement and Phase Rearrangement during Catalytic Activation. Langmuir 2016, 32, 2267-2276.

(34) Talapin, D. V; Shevchenko, E. V; Bodnarchuk, M. I.; Ye, X.; Chen, J.; Murray, C. B. Quasicrystalline Order in SelfAssembled Binary Nanoparticle Superlattices. Nature 2009, 461, 964-967.

(35) Mehta, R. J.; Zhang, Y.; Karthik, C.; Singh, B.; Siegel, R. W.; Borca-Tasciuc, T.; Ramanath, G. A New Class of Doped Nanobulk High-Figure-of-Merit Thermoelectrics by Scalable Bottom-up Assembly. Nat. Mater. 2012, 11, 233-240.

(36) Yang, J.; Choi, M. K.; Kim, D. H.; Hyeon, T. Designed Assembly and Integration of Colloidal Nanocrystals for Device Applications. Adv. Mater. 2016, 28, 1176-1207.

(37) Talapin, D. V.; Lee, J.-S.; Kovalenko, M. V.; Shevchenko, E. V. Prospects of Colloidal Nanocsrystals for Electronic and Optoelectronic Applications. Chem. Rev. 2010, 110, 389-458.

Chen, G.; Seo, J.; Yang, C.; Prasad, P. N. Nanochemistry and Nanomaterials for Photovoltaics. Chem.Soc. Rev. 2013, 42, $8304-8338$.
Lechner, R. T.; Fritz-Popovski, G.; Jarzab, D.; Szendrei, K.; Resel, R.; Korovyanko, O.; et al. Infrared Emitting and Photoconducting Colloidal Silver Chalcogenide Nanocrystal Quantum Dots from a Silylamide-Promoted Synthesis. ACS Nano 2011, 5, 3758-3765.

(40) Zhu, C. N.; Jiang, P.; Zhang, Z. L.; Zhu, D. L.; Tian, Z. Q.; Pang, D. W. Ag2Se Quantum Dots with Tunable Emission in the Second near-Infrared Window. ACS Appl. Mater. Interfaces 2013, 5, 1186-1189.

(41) Dong, B.; Li, C.; Chen, G.; Zhang, Y.; Zhang, Y.; Deng, M.; Wang, Q. Facile Synthesis of Highly Photoluminescent $\mathrm{Ag}_{2} \mathrm{Se}$ Quantum Dots as a New Fluorescent Probe in the Second Near-Infrared Window for in Vivo Imaging. Chem. Mater. 2013, 25, 2503-2509.

(42) Yan, S.; Zhang, L.; Tang, Y.; Lv, Y. Synthesis of WaterSoluble Ag2 Se QDs as a Novel Resonance Rayleigh Scattering Sensor for Highly Sensitive and Selective ConA Detection. Analyst 2014, 139, 4210-4215.

(43) Jang, J.; Pan, F.; Braam, K.; Subramanian, V. Resistance Switching Characteristics of Solid Electrolyte Chalcogenide $\mathrm{Ag}_{2} \mathrm{Se}$ Nanoparticles for Flexible Nonvolatile Memory Applications. Adv. Mater. 2012, 24, 3573-3576.

(44) Husmann, A.; Betts, J. B.; Boebinger, G. S.; Migliori, A.; Rosenbaum, T. F.; Saboungi, M.-L. Megagauss Sensors. Nature 2002, 417, 421-424.

(45) Conn, J. B.; Taylor, R. C. Thermoelectric and Crystallographic Properties of Ag2Se. J. Electrochem. Soc. 1960, 107, C19o.

(46) Ferhat, M.; Nagao, J. Thermoelectric and Transport Properties of $\beta$-Ag2Se Compounds. J. Appl. Phys. 20oo, 88, 813-816.

(47) Day, T.; Drymiotis, F.; Zhang, T.; Rhodes, D.; Shi, X.; Chen, L.; Snyder, G. J. Evaluating the Potential for High Thermoelectric Efficiency of Silver Selenide. J. Mater. Chem. C 2013, 1, 7568-7573.

(48) Cadavid, D.; Ibáñez, M.; Shavel, A.; Durá, O. J.; López de la Torre, M. A.; Cabot, A. Organic Ligand Displacement by Metal Salts to Enhance Nanoparticle Functionality: Thermoelectric Properties of Ag2Te. J. Mater. Chem. A 2013, 1, 4864-4870.

(49) Sun, Y.; Fang, H.; Pan, L.; Han, M.; Xu, S.; Wang, X.; Xu, B.; $\mathrm{Wu}$, Y. Impact of Surface-Bound Small Molecules on the Thermoelectric Property of Self-Assembled Ag2Te Nanocrystal Thin Films. Nano Lett. 2015, 15, 3748-3756.

(5o) Xiao, C.; Xu, J.; Li, K.; Feng, J.; Yang, J.; Xie, Y. Superionic Phase Transition in Silver Chalcogenide Nanocrystals Realizing Optimized Thermoelectric Performance. J. Am. Chem. Soc. 2012, 134, 4287-4293.

(51) Guin, S. N.; Chatterjee, A.; Negi, D. S.; Datta, R.; Biswas, K. High Thermoelectric Performance in Tellurium Free PType AgSbSe2. Energy Environ. Sci. 2013, 6, 2603-26o8.

(52) Xiao, C.; Xu, J.; Cao, B.; Li, K.; Kong, M.; Xie, Y. SolidSolutioned Homojunction Nanoplates with Disordered Lattice: A Promising Approach Toward "phonon Glass Electron Crystal" thermoelectric Materials. J. Am. Chem. Soc. 2012, 134, 7971-7977.

(53) Ishiwata, S.; Shiomi, Y.; Lee, J. S.; Bahramy, M. S.; Suzuki, T.; Uchida, M.; Arita, R.; Taguchi, Y.; Tokura, Y. Extremely High Electron Mobility in a Phonon-Glass Semimetal. Nat. Mater. 2013, 12, 512-517.

(54) Han, C.; Sun, Q.; Cheng, Z. X.; Wang, J. L.; Li, Z.; Qing, G.; $\mathrm{Lu}, \mathrm{M}$. Ambient Scalable Synthesis of Surfactant-Free Thermoelectric CuAgSe Nanoparticles with Reversible 
Metallic- N-P Conductivity Transition. J. Am. Chem. Soc. 2014, 136, 17626-17633.

(55) Liu, M.; Guyot-Sionnest, P. Preparation and Optical Properties of Silver Chalcogenide Coated Gold Nanorods. J. Mater. Chem. 2006, 16, 3942-3945.

(56) Liu, M.; Zeng, H. C. A General Synthetic Approach to Heterostructured Nanocrystals Based on Noble Metals and I-VI, II-VI and I-III-VI Metal-Chalcogenides. Langmuir 2014, 30, 9838-9849.

(57) Xu, L.; Yin, Z.; Cao, S. W.; Fan, Z.; Zhang, X.; Zhang, H.; Xue, C. Rational Synthesis of Triangular Au-Ag2S Hybrid Nanoframes with Effective Photoresponses. Chem. - A Eur. J. 2014, 20, 2742-2745.

(58) Johan, Z.; Kvacek, M.; Picot, P.; Pierrot, R. Fischesserite, First Gold Selenide, Isostructural with Petzite. Bull. la Société française minéralogie Cristallogr. 1971, 94, 381-384.

(59) Bindi, L.; Cipriani, C. Structural and Physical Properties of Fischesserite, a Rare Gold-Silver Selenide from the De Lamar Mine, Owyhee County, Idaho, USA. Can. Mineral. 2004, 42, 1733-1737.

(6o) Tavernier, B. H. Über Silber-Gold(I)-Chalkogenide. Zeitschrift für Anorg. und Allg. Chemie 1966, 343, 323-328.

(61) Feng, D.; Taskinen, P. Thermodynamic Properties of $\mathrm{Ag}_{3} \mathrm{AuSe} 2$ from 300 to $500 \mathrm{~K}$ by a Solid State Galvanic Cell. J. Alloys Compd. 2014, 583, 176-179.

(62) Fang, C. M.; Groot, R. A. De; Wiegers, G. A. Ab Initio Band Structure Calculations of the Low-Temperature Phases of $\mathrm{Ag}_{2} \mathrm{Se}, \mathrm{Ag}_{2} \mathrm{Te}$ and $\mathrm{Ag}_{3} \mathrm{AuSe2}$. J. Phys. Chem. Solids 2002, 63, 457-464.

(63) Sahu, A.; Khare, A.; Deng, D. D.; Norris, D. J. Quantum Confinement in Silver Selenide Semiconductor Nanocrystals. Chem. Commun. 2012, 48, 5458-546o.

(64) Yang, J.; Sargent, E. H.; Kelley, S. O.; Ying, J. Y. A General Phase-Transfer Protocol for Metal Ions and Its Application in Nanocrystal Synthesis. Nat. Mater. 2oo9, 8, 683-689.

(65) Kirkland, E. J. Advanced Computing in Electron Microscopy; Springer: New York, 2010.
Microscopía Electrónica de Alta Resolución de Materiales Policristalinos. Estudio de Catalizadores Metálicos Soportados, University of Cadiz, 1994.

(67) Bernal, S.; Botana, F. J.; Calvino, J. J.; López-Cartes, C.; Pérez-Omil, J. A.; Rodríguez-Izquierdo, J. M. The Interpretation of HREM Images of Supported Metal Catalysts Using Image Simulation: Profile View Images. Ultramicroscopy 1998, 72, 135-164.

(68) Sahu, A.; Qi, L.; Kang, M. S.; Deng, D.; Norris, D. J. Facile Synthesis of Silver Chalcogenide ( $\left.\mathrm{Ag}_{2} \mathrm{E} ; \mathrm{E}=\mathrm{Se}, \mathrm{S}, \mathrm{Te}\right)$ Semiconductor Nanocrystals. J. Am. Chem. Soc. 2011, 133, 6509-6512.

(69) Ravel, B.; Newville, M. ATHENA, ARTEMIS, HEPHAESTUS: Data Analysis for X-Ray Absorption Spectroscopy Using IFEFFIT. J. Synchrotron Radiat. 2005, 12, 537-541.

(70) Wang, J.; Fan, W.; Yang, J.; Da, Z.; Yang, X.; Chen, K.; Yu, H.; Cheng, X. Tetragonal - Orthorhombic - Cubic Phase Transitions in $\mathrm{Ag}_{2} \mathrm{Se}$ Nanocrystals. Chem. Mater. 2014, 26, 5647-5653.

(71) Newman, J. D. S.; Blanchard, G. J. Formation of Gold Nanoparticles Using Amine Reducing Agents. Langmuir 2006, 22, 5882-5887.

(72) Klug, H. P.; Alexander, L. E. X-Ray Diffraction Procedures for Polycrystalline and Amorphous Materials; nnd ed.; John Wiley \& Sons, Inc.: New York, 1974.

(73) Cullity, B. D.; Stock, S. R. Elements of X-Ray Diffraction; 3rd ed.; Prentice-Hall Inc.: New York, 2001.

(74) Egerton, R. F. Electron Energy-Loss Spectroscopy in the Electron Microscope (3rd Edition); 2011.

(75) Hull, S. Superionics: Crystal Structures and Conduction Processes. Reports Prog. Phys. 2004, 67, 1233-1314.

(76) Li, F.; Hu, C.; Xiong, Y.; Wan, B.; Yan, W.; Zhang, M. PhaseTransition-Dependent Conductivity and Thermoelectric Property of Silver Telluride Nanowires. J. Phys. Chem. C 2008, 112, 16130-16133. 


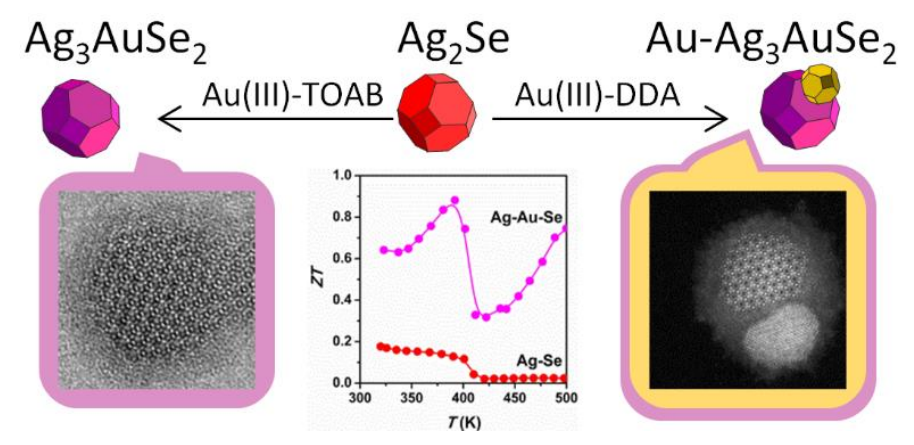

